\title{
Influence of Indian Ocean Dipole and Pacific recharge on following year's El Nino: interdecadal robustness
}

\author{
Takeshi Izumo ${ }^{\text {l, now at } 2 \text {, Matthieu Lengaigne }}{ }^{2}$, Jérôme Vialard ${ }^{2}$, Jing-Jia Luo ${ }^{3, \text { now at } 4}$, Toshio \\ Yamagata, now at 3 and Gurvan Madec ${ }^{2}$ \\ 1. University of Tokyo, Tokyo, Japan. \\ 2. Laboratoire d'Océanographie: Expérimentation et Approches Numériques (LOCEAN), IRD, CNRS, UPMC, Paris, \\ France. \\ 3. Research Institute for Global Change, JAMSTEC, Yokohama, Japan. \\ 4. CAWCR, Bureau of Meteorology, Melbourne, Australia.
}

Accepted, Climate Dynamics

November 30, 2012

Corresponding author address:

Dr. Takeshi Izumo,

LOCEAN, Case 100 - UPMC, 4 Place Jussieu, 75252 Paris cedex 05, France.

e-mail: Takeshi.Izumo@locean-ipsl.upmc.fr 


\begin{abstract}
The Indian Ocean Dipole (IOD) can affect the El Niño-Southern Oscillation (ENSO) state of the following year, in addition to the well-known preconditioning by equatorial Pacific Warm Water Volume (WWV), as suggested by a study based on observations over the recent satellite era (1981-2009). The present paper explores the interdecadal robustness of this result over the 18722008 period. To this end, we develop a robust IOD index, which well exploits sparse historical observations in the tropical Indian Ocean, and an efficient proxy of WWV interannual variations based on the temporal integral of Pacific wind stress of the $20^{\text {th }}$ century reanalysis. A linear regression hindcast model based on these two indices in boreal fall explains $50 \%$ of ENSO peak variance 14 months later, with significant contributions from both the IOD and WWV over most of the historical period and a similar skill for El Niño and La Niña events. Our results further reveal that, when combined with WWV, the IOD index provides a larger ENSO hindcast skill improvement than the Indian Ocean basin-wide mode, the Indian Monsoon or ENSO itself. Based on these results, we propose a revised scheme of Indo-Pacific interactions. In this scheme, the IODENSO interactions favour a biennial timescale and interact with the slower recharge-discharge cycle intrinsic to the Pacific Ocean.
\end{abstract}




\section{Introduction}

In a seminal paper, Sir Gilbert Walker wrote "By the Southern Oscillation it is implied the tendency of pressure at stations in the Pacific (...), and of rainfall in India and Java (...) to increase while pressure in the region of the Indian Ocean (...) decreases" (Walker 1924). He had come to identify what would be later known as the El Niño-Southern Oscillation (ENSO) phenomenon, and was clearly describing it as a phenomenon encompassing both the Indian and Pacific oceans.

During the Tropical Ocean Global Atmosphere (TOGA) decade, the scientific community followed the track laid by Bjerknes (1969) and Wyrtki (1975) in designating the tropical Pacific as the driver of the ENSO phenomenon, and identifying its basic mechanisms. The basic physics of the evolution of El Niño / La Niña events are now reasonably well understood (see, e.g., reviews of Neelin et al. 1998, Wang and Picaut 2004 and Collins et al. 2010). The so-called Bjerknes feedback (positive feedback between warm sea surface temperature (SST) anomalies in the central-eastern Pacific and westerly wind anomalies in the western Pacific) provides the necessary instability for an El Niño to develop. But favourable grounds are needed for the Bjerknes feedback to be able to result in an El Niño. The role of the tropical Pacific heat content, as initially suggested by Wyrtki (1975), is now widely recognized under the framework of the recharge/discharge oscillator (Jin, 1997a,b). The warm water volume (WWV) of the equatorial Pacific, defined as the volume of water above $20^{\circ} \mathrm{C}$ within $5^{\circ} \mathrm{S}$ to $5^{\circ} \mathrm{N}$ by Meinen and McPhaden (2000), is a critical parameter in the ENSO phenomenon. An anomalously high WWV favours warming of the SST in the central Pacific (Wyrtki 1985, Jin 1997a,b), which is further enhanced by air-sea interactions to culminate into a fully developed El Niño by the end of the year. WWV interannual variations are largely driven by equatorial zonal wind (Jin 1997a,b, Goddard and Philander 2000, Clarke 2008, Brown and Fedorov 2010, Fedorov 2010, Lengaigne et al. 2011). The westerly wind anomalies associated with an El Niño event then result in poleward heat transport that "discharges" the equatorial Pacific WWV, thus creating favourable grounds for a La Niña event to develop. A La Niña would in turn favour a WWV recharge and thus later the transition to an El Niño event.

The global influence of ENSO was also established during the TOGA decade. The heat sources and sinks associated with displacements of atmospheric deep convection in the tropical Pacific force atmospheric planetary waves, which are associated with global teleconnections (Trenberth et al. 1998). Zonal displacements and variations of the Walker circulation strength induced by El Niños also strongly affect the Indian Ocean. Increased subsidence and reduced wind speed over the Indian Ocean result in a basin scale warming (e.g. Klein et al. 1999, Ohba and Ueda 2005, 2009b) which persists beyond the end of the El Niño (e.g. Xie et al., 2009). The effect of ENSO on the Indian summer monsoon has also been noted (e.g. Walker 1924, Gershunov et al. 2001, Fasullo 2004, Xavier et al. 2007, Boschat et al. 2012, Cherchi and Navarra 2012). The overall view that emerged from the TOGA decade was thus of an intrinsic mode of the Pacific variability (the ENSO phenomenon) to which the Indian Ocean responds rather passively.

This view changed at the turn of the century, with the discovery of an intrinsic mode of climate variability in the Indian Ocean, commonly referred to as the Indian Ocean Dipole (IOD) mode. As for ENSO, a positive air-sea feedback partly similar to the Bjerknes one fosters the development of IOD events: the positive phase of the IOD is characterized by cold (warm) anomalies in the eastern (western) Indian Ocean and equatorial easterly wind anomalies in the central Indian Ocean that mutually enhance each other (Reverdin et al. 1986, Saji et al. 1999, Webster et al. 1999, Murtugudde and Busalacchi 1999, Murtugudde et al. 2000). Like ENSO, the IOD is phase-locked to the seasonal cycle. It develops during boreal summer, culminates in fall, and decays by the end of the year. There is now ample evidence that the IOD is an intrinsic mode of variability of the Indian Ocean (e.g. Annamalai et al. 2003, Fischer et al. 2005, Behera et al. 2006, Luo et al. 2008, 2010). There is however a tendency of IOD events to co-occur with ENSO events 
(Fig. $1 \mathrm{~b}$ and e.g. Reverdin et al. 1986, Murtugudde et al. 2000, Annamalai et al. 2003, Yamagata et al. 2004, Fischer et al. 2005, Xie et al. 2009). El Niño events indeed favour easterlies over the equatorial Indian Ocean which can trigger a positive IOD (Annamalai et al. 2003). While the Indian Ocean is no longer viewed as a climatically inactive ocean (e.g. Annamalai and Murtugudde 2004), this still illustrates an influence of the Pacific on the Indian Ocean.

Many recent studies have however suggested that Indian Ocean SSTs may influence the tropical Pacific (e.g. Watanabe et al. 2008a,b, Jansen et al. 2009) and its evolution. Coupled General Circulation Model (CGCM) sensitivity experiments with a decoupled Indian Ocean suggest that Indian Ocean SST interannual variations might alter ENSO variance, phase locking and spectral characteristics (Wu and Kirtman 2004, Yu et al. 2002, Yu 2005, Behera et al. 2006). Observational, atmospheric modelling (Watanabe and Jin 2002, Kug and Kang 2006) and CGCM analyses (Kug et al. 2006, Ohba and Ueda 2005, 2007, 2009a, 2009b, Yamanaka et al. 2009, Ohba et al. 2010, Luo et al. 2010, Okumura and Deser 2010, Okumura et al. 2011, Ohba and Watanabe 2012, Santoso et al. 2012, Kug and Ham 2012) showed that the Indian Ocean basin-wide warming (IOBW), which appears during El Niño peak and lasts afterwards, tends to favour the phase transition to a La Niña through easterly anomalies in the western Pacific and to damp ENSO amplitude. Annamalai et al. $(2005,2010)$ showed that SST anomalies over the Indian Ocean (either uniform or related to the IOD) influence the atmospheric circulation over the Pacific. Dedicated model experiments (Luo et al. 2010, Annamalai et al. 2010) further suggested that El Niños tend to be stronger when they co-occur with IOD events (Behera and Yamagata 2003). Other studies (Ohba and Ueda 2009a, Ohba et al. 2010, Okumura and Deser 2010, Okumura et al. 2011, Ohba and Watanabe 2012) have discussed the possible role of the Indian Ocean basin-wide warming/cooling onto El Niño/La Niña asymmetries.

While most of the above studies focus on the synchronous influence of the Indian Ocean on the Pacific, a few studies have explored potential precursors of ENSO in the Indian Ocean. Several early studies have indeed noticed that interannual anomalies that lead to an El Niño event appeared to be originating from the Indian Ocean (Barnett 1983, Yasunari 1985, Krishnamurti et al. 1986, Watanabe 2008b) and maritime continent (Nicholls 1984). This feature was exploited in a statistical forecasting scheme by Clarke and van Gorder (2003): in their scheme, zonal wind anomalies in the Indian Ocean are used as a predictor to the ENSO peak occurring one year later. Terray and Dominiak (2005) also noted that cold SST anomalies in the southeastern Tropical Indian Ocean in February-March serve as an efficient predictor of the El Niño peak 10 months later. The influence of the Indian Ocean on the Pacific the following year was also suggested to be through the monsoon, and was built into the Tropical Tropospheric Biennial Oscillation (TBO; e.g. Meehl 1987, Meehl et al. 2003), a framework to explain the biennial tendency in the system formed by the Indian and Australian monsoons, Indian Ocean SST, and ENSO. However, the mechanism for the observed eastward propagation of zonal wind from the Indian Ocean to the Pacific remained unclear (Clarke 2008).

Izumo et al. (2010a; hereafter I10) recently suggested that a negative (positive) IOD in the Indian Ocean tends to favour an El Niño (La Niña) about 14 months later (Fig. 1d). They have further demonstrated that using an IOD index in addition to the WWV predictor in fall results in a significant improvement of the prediction skill score of the ENSO peak in winter about 14 months later. They suggested the following mechanism to explain the influence of the Indian Ocean on the Pacific. In boreal fall (the peak season for the IOD), the strongest atmospheric convection in the tropics is found in the eastern equatorial Indian Ocean (Fig. 1a), where the highest sensitivity of precipitation to local SST is found (Fig. 1b) and where IOD SST and related convection anomalies are strongest (Fig. 1c). A developing IOD in this region can thus have a significant influence on the ascending branch of the Walker circulation, and hence on its strength. A negative IOD (i.e. with positive SST anomalies in the eastern Indian Ocean) hence externally forces equatorial Pacific easterly anomalies in fall, which suddenly relax in winter in association with the IOD demise. Wave 
reflections in essence similar to the delayed (Schopf and Suarez 1988, Battisti and Hirst 1989) and advective-reflective oscillators (Picaut et al. 1997) act to reinforce the Pacific Ocean response to the IOD-related winds and their relaxation, and drive eastward current anomalies and positive SST anomalies in the central Pacific through zonal advection of the warm pool eastern edge (the main process that controls SST variations in the central Pacific, e.g. Vialard et al. 2001). These SST anomalies may be amplified by the Bjerknes feedback and culminate into an El Niño event at the end of the year. One must note that the scenario presented above describes the influence of external forcing of the tropical Indian Ocean on the Pacific Ocean. This effect will combine to the existing internal dynamics of the tropical Pacific during the onset phase, i.e. the preconditioning by the Pacific WWV as described by the recharge oscillator theory (as do westerly wind bursts, e.g. Fedorov 2002). At the end, the two effects (external forcing from the Indian Ocean and local preconditioning in the Pacific) will combine (or oppose each other) to influence the ENSO evolution during the following year.

I10 obtained their results using recent high-quality satellite and in situ observations only available since 1981. Many papers have however documented decadal changes in ENSO (e.g. An and Wang 2000, Wang and Picaut 2004, Leloup et al. 2007) or IOD (e.g. Abram et al. 2008, Ummenhofer et al. 2009) characteristics; or changes in links between the two modes (e.g. Terray et al. 2005, Annamalai et al. 2005). As stated by Webster and Hoyos (2010), it is important to test whether these interactions are a feature of the Indian and Pacific climate that is not restricted to the recent period. The first objective of this paper is hence to investigate the interdecadal robustness of I10's scenario over a much longer period. In order to do that, we define, after presenting datasets and methods in section 2, an improved IOD index that efficiently exploits sparse historical observations in the Indian Ocean (section 3.1). Similarly, observed WWV is not available prior to the 1980's due to insufficient subsurface observations. Section 3.2 shows that WWV can be efficiently reconstructed by integrating zonal wind stress of the equatorial Pacific. We hence reconstruct WWV from reanalysis wind stress since the 1870s. In section 4 we investigate the robustness and the decadal stability of the IOD/WWV/ENSO relationships using these historical indices, as well as possible asymmetries in the skills of El Niño / La Niña predictions. We also investigate a long coupled model simulation, and find similar results to the observations. Section 5.1 shows that the IOD is a better predictor of following year's ENSO state than other climate indices (including the Indian monsoon) over the historical 1870's-2000's period. Section 5.2 discusses our results about the Indian Ocean - Indian monsoon - ENSO relations in the context of the TBO. Section 6 provides a summary and a discussion of our results.

\section{Datasets and methods}

\subsection{Datasets}

Depending on the period considered and to assess the robustness of the results, several SST observational datasets have been analysed. For the recent period, we use the recent optimal interpolation (OI) SSTv2 from National Oceanic and Atmospheric Administration (NOAA) that blends in situ and satellite data sources (Reynolds et al. 2002) and is available from November 1981 onward. Over the historical period, we use the HadiSSTv1.1 product (Rayner et al. 2003) that is based on sparse ship datasets before 1981 and is available from 1870 onwards. Reduced-space optimal interpolation allows filling gaps in data-sparse oceanic regions. Because of the limitations inherent to this approach, we recomputed our analyses with two other products: ERSSTv3b (Smith et al. 2008) that uses an interpolation strategy similar to HadiSSTv1.1, and HadSST2 (Rayner et al. 2006) that does not use any interpolation. Results derived from these datasets are consistent with 
each other, except during the Second World War when data were extremely sparse (cf. sections 3 and 4). We also analyse the density of in-situ SST observations from ICOADS (International Comprehensive Atmosphere-Ocean Data Set, http://icoads.noaa.gov) database, on which the three SST products are based. The quality and sampling issues before the satellite era are discussed in section 3, by exploiting the accurate estimates of uncertainties available in the HadSST2 product.

The subsurface oceanic conditions in the equatorial Pacific are described using the Warm Water Volume index (the volume of water above the $20^{\circ} \mathrm{C}$ isotherm in the $\left[120^{\circ} \mathrm{E}-80^{\circ} \mathrm{W}, 5^{\circ} \mathrm{N}-5^{\circ} \mathrm{S}\right]$ region; hereafter WWV), made available since 1980 at http://www.pmel.noaa.gov/tao/elnino/wwV/ (Meinen and McPhaden 2000). This index is derived from the Australian Bureau of Meteorology Reasearch Center tropical Pacific subsurface temperature dataset (Smith 1995) that includes XBT measurements and data from the Tropical Atmosphere Ocean (TAO) array. A historical proxy for the WWV will be constructed from 1871 to present using zonal wind stress from the $20^{\text {th }}$ Century atmospheric reanalysis version 2 (20CR; Compo et al. 2011) that is forced by HadiSSTv1.1 SST dataset and assimilates sea level pressure measurements. This proxy will be validated over the recent period against the observed WWV estimate described above. Interpolated outgoing longwave radiation (OLR) from NOAA (Liebmann and Smith 1996) is used as a proxy for deep atmospheric convection in the tropics, and is available since 1974 (with a gap in 1978). The GPCP precipitation dataset (Huffman et al. 1997) and ERS1-2 scatterometer winds (1992-2001, Bentamy et al. 1996) are also used in Figure 1.

The strength of the Indian summer monsoon is characterized using the All Indian Rainfall (AIR) dataset, and the rainfall over the Indian homogeneous regions defined by the IITM, available from 1871 to 2008 (Parthasarathy et al. 1994). For the analysis of historical rainfall variability globally in relation with previous year's IOD and WWV, we use GPCC in-situ gauge based land precipitation dataset (Rudolf et al. 2010) and the precipitation from 20CR reanalysis. Similarly, for historical sea level pressure (SLP) variability, we use ICOADS SLP in situ observations at sea, as well as SLP from 20CR reanalysis.

Finally, we also analyse a 220 years-long climate simulation performed with the SINTEX-F coupled general circulation model (GCM). This model is based on the OPA8.2 (Madec et al. 1998; former NEMO) ocean GCM (ORCA2 grid; resolution of $2^{\circ}$ zonally and $0.5^{\circ}$ meridionally near the equator) coupled to the ECHAM4 atmosphere GCM (Roeckner et al. 1996) at a T106 resolution $\left(1.125^{\circ}\right)$. A detailed description of this model can be found in Luo et al. (2005) and Masson et al. (2005). We use here years 7 to 221 of the control experiment (CTL) used in Luo et al. (2005).

\subsection{Methods and indices}

For datasets covering the recent period (1981-2010), interannual variations have simply been computed by subtracting the mean seasonal cycle from the original time series. Further linearly detrending the time series yields very similar results. For datasets covering the historical period (1871-2008) and coupled GCM outputs, trends and decadal-to-multidecadal fluctuations have been removed using a Hanning filter (almost all energy is preserved at periods lower than 7 years, and half-power cut at 13 years). Due to filter edge effects, the first and last 6 years of the time series are not considered in the analysis. Other types of filtering methods (e.g. cutting at 5 or 9 years instead of 7) give similar results.

Statistical relationships between two variables are described using linear regression and simple correlations. To extract a signal related to one index independently from another one, we also use partial correlations (see, e.g. Yamagata et al. 2004) as well as multiple linear regressions (as in I10). Regression coefficients are computed from normalized climate indices (i.e., divided by their standard deviation) so that regression coefficients discussed in the paper hence correspond to the typical amplitude of the signals associated with a given climate mode. Significance tests were computed from Student's two-tailed t-test (assuming one degree of freedom per year throughout the 
paper, as the autocorrelation at lag 1 year for the indices used here was either non-significant or negative). " 1 st order" asymmetries between positive and negative phases of IOD, ENSO or WWV are identified using "one-way means", i.e. usual composites for positive or negative events. More subtle " 2 nd order" asymmetries are identified using one-way correlations, i.e. the correlation for the positive or negative phase (Hoerling et al. 2001, Ohba et al. 2010).

We use several classical definitions to describe the variability associated with the IOD (Dipole Mode Index or DMI), ENSO (Niño3.4), Indian Ocean basin-wide warming/cooling (IOBW) associated with El Nino/La Nina events, and All India Rainfall (AIR). The DMI is defined as the September-November SST anomaly difference between $\left[50^{\circ} \mathrm{E}-70^{\circ} \mathrm{E}, 10^{\circ} \mathrm{S}-10^{\circ} \mathrm{N}\right]$ and $\left[90^{\circ} \mathrm{E}-\right.$ $110^{\circ} \mathrm{E}, 10^{\circ} \mathrm{S}-0^{\circ}$ ] following Saji et al. (1999). Observed ENSO variability is characterized using the November-January SST anomalies in the Niño3.4 region $\left[170^{\circ} \mathrm{W}-120^{\circ} \mathrm{W}, 5^{\circ} \mathrm{S}-5^{\circ} \mathrm{N}\right]$. IOBW variability is characterized as the January-March SST anomaly averaged over the entire tropical Indian Ocean $\left[40^{\circ} \mathrm{E}-110^{\circ} \mathrm{E}, 20^{\circ} \mathrm{S}-20^{\circ} \mathrm{N}\right]$. AIR is defined as the average June-September (JJAS) interannual rainfall anomaly over India. All indices are normalised by their interannual standard deviations. Due to sparse in-situ data coverage before the satellite era, some of the above indices are not properly sampled. More robust and homogeneous indices over the historical period will be proposed in the following section.

\section{Construction of historical IOD and WWV indices}

\subsection{An improved historical IOD index}

\section{a. SST observational coverage}

Figure 2a displays the density of observations for the pre-satellite era (1870-1979) in ICOADS (i.e. the database used to construct most of available SST products). Regions commonly used to define ENSO and DMI indices are poorly spatially sampled (e.g. strong lack of observations in the central equatorial Pacific). The time evolution of the number of observations for the various boxes used to calculate these climate indices (Fig. 2b) reveals that observations are very sparse before the 1870's. It then remains relatively stable until the early 1980's, except for two major drops observed during both world wars. As measurement and sampling random errors available in HadSST2 dataset are assumed to be uncorrelated in space and time, we thus estimate the error from the sum of their squares at each grid point and for each of the three months used for the spatiotemporal average (Fig. 2c). With an estimated sampling error of 30 to $50 \%$ of interannual variability amplitude, the eastern DMI box is the most heavily affected by sampling issues. The western DMI and the equatorial Pacific are better sampled (with sampling errors respectively of $\sim 30 \%$ and $\sim 20 \%$ ), owing to their larger covered areas and larger spatial (Figs 1c and 3) and temporal decorrelation scales than those of the smaller and shorter-living IOD eastern pole, with moreover a historically well-sampled ship route in the north Indian Ocean (Fig. 2a, cf. also Chowdary et al. 2012) capturing IOD western pole variability (Fig. 3). The sampling errors increase dramatically during both world wars, especially affecting eastern pole sampling.

\section{b. $A$ regression-based $I_{O D} D_{\text {hist }}$ index}

The above analyses suggest that conventional ENSO and IOD indices should be interpreted cautiously before 1981, because of the sparse data sampling. Obviously, these data are much more reliable from 1981 onwards, as in-situ data are complemented by satellite data. A possible way to reduce sampling-related uncertainties during the historical period is to define indices with a spatially and/or temporally extended average, as recently proposed for ENSO index by Bunge and Clarke (2009). They used an EOF technique to interpolate spatio-temporally the sparse SST 
observations available before the 1980's, exploiting a much larger area of SST measurements than Nino3.4. Compared to the conventional Nino3.4 SST index, their Nino3.4 $4_{\text {hist }}$ index is thus an improved ENSO index (available from 1872 to 2008), which better matches with a similarly reconstructed $\mathrm{ESOI}_{\text {hist }}$ index based on historical sea level pressure data. We hence use this Nino3.4 $4_{\text {hist }}$ index for historical analyses throughout the present study (using their ESOI hist gives similar results).

To build a robust IOD index over the historical period, we follow a relatively similar strategy based on a spatial linear regression (an EOF-based method led to similar results). Figure 3 shows the regression coefficients in the Indian Ocean of the DMI index onto September-November SST over the recent period (1981-2009). We build a new index, referred to as $\mathrm{IOD}_{\text {hist }}$, by projecting the September-November SST anomalies on that spatial pattern wherever the regression coefficient is significant above the $90 \%$ level over the tropical Indian Ocean. The correlation between IOD $_{\text {hist }}$ and the DMI exceeds 0.9 for both the recent and historical period, and for the three SST datasets. In the present study, both the conventional DMI and the $\mathrm{IOD}_{\text {hist }}$ index are used; they give qualitatively similar results. However, using DMI results in weaker correlations and statistical significances, especially around World War II, a period heavily affected by data sampling issues. We also tested the sensitivity of the results to the SST product used (HadiSST, HadSST2 or ERSSTv3b). All products led to similar results when using $\mathrm{IOD}_{\text {hist, }}$ but to quantitatively different interdecadal variations when using DMI (cf. section 4.1).

\subsection{An historical WWV proxy}

Physically, interannual variations of the WWV (or equivalently equatorial Pacific averaged thermocline depth "h") are mainly caused by Sverdup transport across the basin, which is proportional to the zonal windstress $\tau_{\mathrm{x}}$ along the equatorial Pacific (e.g. Jin 1997a). This is translated into mathematical terms by the WWV recharge-discharge equation (Jin 1997a,b):

$\mathrm{dWWV} / \mathrm{dt}=-\mathrm{rWWV}-\alpha \tau_{\mathrm{x}}$

Burgers et al. (2005) showed from a fit to observations that the damping term $r$ was not significantly different from zero. This implies that WWV could be derived from temporal integration of zonal average wind variations. Indeed, a fit between observed dWWV/dt and 20CR zonal wind stress within the equatorial Pacific wave guide $\left(130^{\circ} \mathrm{E}-80^{\circ} \mathrm{W}, 2^{\circ} \mathrm{S}-2^{\circ} \mathrm{N}\right)$ provides a value for $\alpha=6.1 * 10^{8} \mathrm{~m}^{5} \mathrm{~N}^{-1} \mathrm{~s}^{-1}$ (using a low-pass filter removing periods lower or equal to 1 year, with a 2 years Hanning window). We hence build our historical proxy $W_{W V}$ hist $(t)$ of $W W V(t)$ from the temporal integration of $-\alpha \tau_{\mathrm{x}}$, using 2-7 years band-pass filtered $\tau_{\mathrm{x}}$ interannual anomalies from 1871 to time $\mathrm{t}$ using 20CR data. This index compares very well with the observed WWV interannual variations over the recent decades (Fig. 4), with a correlation coefficient of 0.87 . Note that equation (1) effectively filters out the principal equatorial wave propagations (i.e. first baroclinic meridional modes of Kelvin and Rossby waves along the equatorial Pacific), and can only be used for reconstructing low-frequency WWV variations (i.e. it does not work well at timescales shorter than the basin adjustment).

The validity of our approach for estimating WWV from low-frequency zonal wind stress is further assessed using the SINTEX-F control experiment. In this 220 years simulation, $W_{W} V_{\text {hist }}$ and WWV have a 0.77 correlation. This $\mathrm{WWV}_{\text {hist }}$ is closer to WWV than to $\mathrm{WWV}_{\text {west }}$ or $\mathrm{WWV}_{\text {east }}$ (as defined in Meinen and McPhaden 2000), somehow in agreement with Burgers et al. (2005), and in partial agreement with Fedorov (2010, as the $\mathrm{WWV}_{\text {hist }}$ is accordingly close to the temporal integral of ENSO; but in his study this integral is closer to $\mathrm{WWV}_{\text {west }}$ ). In the following, we will hence use $\mathrm{WWV}_{\text {hist }}$ as a proxy for WWV interannual variations over the historical period. 


\section{IOD and WWV as robust precursors of following year's ENSO}

In this section, we use the historical $\mathrm{IOD}_{\text {hist }}, \mathrm{WWV}$ hist and Nino34 $4_{\text {hist }}$ indices defined in the previous section to explore synchronous and one-year lead relationships between climate variability in the Indian and Pacific oceans over the historical period.

\subsection{Simultaneous and one year lead-lag relationships}

When performed over the entire 1872-2008 period, the synchronous correlation between the IOD and ENSO is significant at the 99\% significance level, whatever the SST dataset (HadiSST, HadSST2 or ERSST) and IOD index (DMI or IOD hist) considered, ranging from 0.54 to 0.70 . This relationship displays interdecadal variations (Fig. 5a), but remains significant at the $90 \%$ significance level throughout the period (except when using the DMI from HadSST2 dataset) when calculating correlations over a 30 years sliding window. The correlation weakens from the 1940's to the 1960's, in agreement with Annamalai et al. (2005) but remains within the range of decadal variations expected from a random process (see table 1 in Gershunov et al. 2001; van Oldenborgh and Burgers 2005). The simultaneous correlation between ENSO and IOD is hence a quite stable feature throughout the historical record. This correlation is dynamically explained by the tendency of ENSO-induced wind anomalies over the Indian Ocean to trigger an IOD (e.g. Annamalai et al. 2003; with possibly also a positive feedback of IOD on ENSO, e.g. Luo et al. 2010).

The one-year lead correlations of the IOD and WWV indices with following year's ENSO are both significant at the $99 \%$ level when performed over the whole historical record (e.g. -0.44 for $\mathrm{IOD}_{\text {hist }}$ using HadiSST and 0.59 for $\mathrm{WWV}_{\text {hist }}$ ). They also display interdecadal variations (Fig. 5b). The IOD correlation with following year's ENSO is significant at the $90 \%$ level over most of the period, except when computed using the DMI with HadSST2 dataset. It remains always higher than ENSO autocorrelation at a one-year lag (not shown). Both IOD indices indicate a decrease of the IOD one-year lead correlation (below the 90\% significance level) around the 1940's when using HadiSST. The one-year lead correlation of $\mathrm{WWV}_{\text {hist }}$ with following year's ENSO remain significant over the entire period, ranging from 0.4 in the early part of the record to 0.7 in the 1940's. In general, the tendency of the IOD to precede ENSO by one year is relatively stable, although not as much as the recharge mechanism or as the simultaneous correlation between ENSO and IOD.

\subsection{ENSO one year-lead hindcast using IOD and WWV indices}

I10 showed the benefit of including IOD information in a multiple linear regression model based on the WWV and IOD indices in SON to predict the ENSO state 14 months later, with a skill score of $\sim 0.8$ over the 1981-2009 period. Their results suggested an equivalent importance of the IOD external forcing and Pacific heat content at one-year lead. A similar analysis is conducted over the entire 1872-2008 period using the $\mathrm{WWV}_{\text {hist }}$ and $\mathrm{IOD}_{\text {hist }}$ indices. Figure 6 shows the time series of the Niño3.4 hist index and the 14-month lead hindcast using WWV hist and $\mathrm{IOD}_{\text {hist }}$ over the entire period. This hindcast has a skill score of 0.72 (significant at the $99 \%$ level), only slightly weaker compared to I10 study for the recent period. The relative contributions of -IOD and WWV, inferred from normalised coefficients, are respectively of $0.40 \pm 0.10$ and $0.57 \pm 0.10$, the difference between the two coefficients being non-significant at the $90 \%$ level. A similar skill of 0.71 is found when using an equal weight for the IOD and the WWV. This underlines that, over the entire historical period, the contributions of WWV and IOD to the following year's ENSO were almost equivalent (as in I10). 
Computing this multiple linear regression using pointwise HadiSST SST instead of the IOD $_{\text {hist }}$ index shows a distinct IOD-like dipolar pattern in the Indian Ocean SST precursor's to El Niño 14 months later (not shown). A higher skill score is however obtained when using the western (0.72) rather than the eastern pole (0.62) of the IOD over the historical period. This difference in skill score may be related to observational issues: as shown in section 3.1, there is a poor observational coverage of the IOD eastern pole over most of the historical (pre-satellite) period, while the western pole interannual SST variations are better sampled. Over the recent 1981-2010 satellite period indeed there are insignificant skill score difference between the two poles, while using an OLRbased indicator of deep atmospheric convection (cf. I10) results in a higher score for the eastern pole of the IOD (not shown). While it is difficult to conclude which pole of the IOD is the most efficient predictor from historical data, it remains clear that both poles bring added predictability during boreal fall, the period of the year with strongest IOD signals.

Figure 7a shows the interdecadal fluctuations of the 14 months-lead ENSO hindcast skill (black line) and the simple correlation of ENSO with IOD (red) and WWV (green) 14 months before. The skill is stable throughout the period with a skill score ranging from $\sim 0.65$ to $\sim 0.8$. Both IOD and WWV's independent contributions always remain significantly above zero at the $90 \%$ level (Fig. 7b). The IOD almost always brings a significant contribution in addition to the WWV. The IOD contribution to the ENSO hindcast reaches a minimum around 1940-1960 (Fig. 7b), i.e. a period with statistically weaker IOD influence and relatively stronger WWV influence (the difference is significant at the $90 \%$ level), whereas the IOD and WWV contribute equally during the early and late part of the record. Interestingly the $\sim 1940-1960$ minimum period corresponds to a period when ENSO amplitude (Fig. 5c) and frequency were lower with weaker biennality (as inferred from wavelet and autocorrelation analyses; not shown).

These results show that the I10 results are valid over the much longer 1872-2008 period, although there appears to be significant decadal fluctuations in the contribution of the IOD to next year's ENSO predictability. Other IOD and ENSO indices give very consistent results.

\subsection{Comparing skills of El Niño / La Niña hindcasts}

In this subsection, we investigate potential asymmetries in the one-year lead/lag relation between IOD and ENSO to infer if the mechanism proposed by I10 operates for both positive and negative phases of ENSO. To qualitatively and quantitatively assess possible asymmetries, we thus display scatterplots between IOD, WWV, hindcasted ENSO amplitudes and observed ENSO amplitudes (Fig. 8). Figure 8a shows qualitatively that the 14-month lead El Niño hindcast performs as well for El Nino and for La Nina. This comes partly from the equivalent efficiency of WWV to predict positive and negative phases of ENSO (Fig. 8c). But this also comes partly from the fact that El Niños (La Niñas) are on average preceded by negative (positive) IODs. There might be a slight asymmetry in the slope of the IOD vs Nino3.4 regression due to Niño3.4 and IOD skewnesses (not shown). But quantitatively, there is no significant $1^{\text {st }}$-order asymmetry between the 14-month lead $\mathrm{IOD}_{\text {hist }}$ value before an El Niño (-0.44 \pm 0.19 , cf. crosses in Fig. $\left.8 \mathrm{~b}\right)$ and a La Niña $(0.36 \pm 0.20$, Fig. $8 \mathrm{~b})$. We also computed one-way correlations, but could not identify any consistent and significant $2^{\text {nd }}$ order asymmetries when comparing the various indices (not shown). The lead-lag IOD-ENSO relationship hence operates for both positive and negative phases of ENSO (and for both positive and negative phases of IOD).

\subsection{CGCM results}

To further test the robustness of the results, we have performed similar analyses in the SINTEX-F coupled model simulation briefly presented in section 2 . This simulation provides the exact WWV as well as the DMI index without any observational uncertainties. We can hence 
evaluate the simple ENSO hindcast model proposed in I10 and its interdecadal fluctuations from this model dataset. Figures 9 and 10 are similar to Figures 5 and 7 but for the model results. The simultaneous correlation between ENSO and IOD (Fig. 9a, red curve) is weaker than that in observations, and goes below the significance level during several decades, which coincide with periods of weaker ENSO and IOD activity (Fig. 9c).

The one-year lead correlations of IOD and WWV with following year's ENSO in this model are rather consistent with observations, although the IOD one is somewhat larger. They remain significant over most of the simulation period but display interdecadal fluctuations (Fig. 9b). Using IOD and WWV to hindcast ENSO 14 months later for the entire model period results in a good skill score of 0.66 with a similar contribution from WWV and IOD, as in observations (cf. section 4.1; the $\mathrm{WWV}_{\text {hist }}$ proxy is also a good predictor in this model, being even better than the original WWV, with a higher skill of 0.74 ). The skill score displays interdecadal fluctuations, ranging from 0.6 to 0.8 (Fig. 10a). There are more significant fluctuations in the relative contributions of IOD and WWV to the skill in the CGCM than in observations, with WWV dominating in some periods and IOD in others (Fig. 10b).

To summarize, CGCM results confirm that the IOD and WWV contribute to 14-month lead ENSO forecasts, with the hindcast correlation skill varying interdecadally between 0.6 and 0.8 (Fig. 7a). These correlation variations are however within the range of those expected from pure stochastic processes (Gershunov et al. 2001).

\section{A revised framework for Indo-Pacific interactions}

\subsection{Other possible precursors}

In this subsection, we evaluate the efficiency of several regional SST indices (IOBW and ENSO in winter, and Indian Monsoon in summer) to predict El Niño one year later. We do this by estimating the significance of the increase in skill brought by combining each of these indices to WWV, compared to a hindcast based on WWV alone (Table 1).

Recent papers have shown that the Indian-Ocean basin wide warming during an El Niño can affect the phase transition to La Niña (e.g. Annamalai et al 2005; Ohba and Ueda 2007, 2010; Yamanaka et al. 2009; Kug and Kang 2006; Kug et al. 2006). We have hence compared the skill of the IOBW and IOD in predicting ENSO. Both simple ( -0.44 for IOD against -0.32 for IOBW, table 1) and partial correlation analysis ( -0.31 for IOD without IOBW against -0.02 for IOBW without IOD) indicate that the IOD (in SON of year -1) is a better precursor of ENSO events one year later than the IOBW (in JFM of year 0). Furthermore, results from our simple statistical prediction scheme (Table 1) indicate that the skill improvement brought by IOBW through a multiple regression "IOBW+WWV" is not significant when compared to WWV alone at the same season. Conversely, the skill improvement brought by the IOD to the WWV predictor taken in SON or JJAS (of year -1) is significant above the 95\% significance level (Table 1). Using the IOBW index at a slightly different season (NDJ, DJF or FMA) does not change the above conclusions. This result may seem at odd with the extensive literature that shows that the IOBW acts as a negative feedback on ENSO, concurring to the demise of ENSO events and promoting a rapid phase transition, possibly asymmetric (Kug and Kang 2006, Ohba and Ueda 2007, 2009a, Yamanaka et al. 2009, Ohba et al. 2010, Luo et al. 2010, Okumura and Deser 2010, Okumura et al. 2011, Ohba and Watanabe 2012). Our interpretation follows: as the IOBW is intimately tied to the ENSO cycle (ENSO/IOBW squared correlation, i.e. explained variance, of 66\%), its influence on ENSO is rather systematic. Each El Niño/La Niña event promotes an Indian Ocean Basin Wide Warming/Cooling 
that systematically acts to promote the transition to ENSO opposite phase one year later. This tight ENSO/IOBW relationship is probably the reason why including an IOBW index does not significantly improve ENSO prediction. In contrast, the IOD is more independent from the ENSO cycle (IOD/ENSO squared correlation of 49\%) and hence brings an external forcing (on Pacific wind, cf. I10) more independent of the ENSO cycle. The fact that the IOD is a more robust ENSO predictor than the IOBW does not preclude a systematic influence of the IOBW on ENSO. As for the IOBW, ENSO itself is not a significant predictor of following year's ENSO throughout the whole historical record (Table 1). These results are stable interdecadally, being also valid for 30 years-long periods (not shown).

In the conceptual scheme proposed by Webster and Hoyos (2010) and in the TBO framework (e.g. Webster et al. 2002, Loschnigg et al. 2003), the Indian summer monsoon (or in a broader context the Asian monsoon) can indirectly influence the following year's ENSO. Indicators of the Indian monsoon may hence provide some predictive skill for following year's El Niño. However, neither the summer monsoon historical index (AIR) nor historical rainfall regional data (over the Indian regions defined by IITM; not shown) brings any significant increase in the hindcast skill of El Niño 16 months later, whereas IOD does (Table 1). As another independent confirmation, we also used the satellite-based NOAA OLR data (from 1974) as a proxy of deep atmospheric convection, and wind (from 1979, NCEP2 reanalysis, Kanamitsu et al. 2002) as an indicator of monsoon circulation. These tests also suggest that the Indian/Asian summer monsoon does not seem to significantly influence the following year's ENSO ( 18 months later).

\subsection{Biennial interactions between ENSO and Indian Ocean variability}

The influence of the IOD on following year's ENSO can naturally produce a biennial tendency of the IOD-ENSO system, as suggested by I10. In this section, we will review and discuss biennial relations between ENSO and the variability in Indian Ocean (IOD, IOBW and the Indian/Asian monsoon), in light of the results presented in this paper.

The influences of ENSO on same year IOD and Indian summer monsoon are rather stable interdecadally (Figures 5a and 11). The tendency of El Niño (resp. La Niña) events to be associated with the weak (resp. strong) Indian monsoon described by Walker (1924) was stable throughout the historical record, with a -0.7 correlation between ENSO and monsoon indices over the 1870-1980 period (red curve in Fig. 11). As already discussed by Krishna Kumar et al. (1999), our results confirm a weakening of this link over the recent satellite period that is however within the range of stochastic fluctuations (Gershunov et al. 2001, van Oldenborgh and Burgers 2005).

Some authors have proposed that the Indian summer monsoon may influence the IOD but do not agree on the sign of this influence. Webster et al. (2002), Loschnigg et al. (2003) and Webster and Hoyos (2010) propose that a strong Indian monsoon circulation induce westerlies along the equatorial Indian Ocean, in turn favouring a negative IOD. Annamalai et al. (2003) and Krishnan and Swapna (2009) showed that a strong Indian monsoon could favour a positive IOD through southeasterlies along Sumatra coast (another CGCM experiment [Izumo et al. 2008, their Fig. 2d] also suggests such influence). Other authors have also proposed that the IOD influences the monsoon, usually positively (Behera et al. 1999, Ashok et al. 2001, 2004, Annamalai et al. 2003, 2010, Gadgil et al. 2004, Ashok and Saji 2007, Ummenhofer et al. 2011, Boschat et al. 2012). Meehl et al. (2003) also noted an apparent relation between the two, but do not distinguish whether the monsoon influences IOD or the opposite. Here, we note that, compared to the synchronous ENSO-IOD and ENSO-monsoon relations and to the IOD's impact on ENSO at one year lead, the synchronous IOD- monsoon relation appears to be weak and not very stable interdecadally (Fig. 11). The simple and partial correlations between JJAS AIR and the IOD are indeed not significant during long periods of the historical record (Fig. 11). They are also rather weak when taken over the complete record (simple correlation of -0.09 and partial correlation of +0.23 ). These results suggest 
that the interactions between the monsoon and the IOD are much weaker than those between the IOD and ENSO.

In the light of the discussion above, AIR-IOD-IOBW-ENSO relationships appear to only fit partially within the frame of the TBO. We thus suggest a slightly revised conceptual scheme of Indo-Pacific relations outlined in the TBO framework (e.g. Loschnigg et al 2003) or in Webster and Hoyos (2010). This conceptual picture is summarized in Figure 12. The outer circle in this scheme represents the slow ( $\sim 3-5$ years) recharge-discharge oceanic adjustment process of the large equatorial Pacific (Jin 1997a,b), with asymmetries between a fast WWV discharge (in 1 to $1 \frac{1}{2}$ year) and the slow recharge (1 to 3 years; e.g. Meinen and McPhaden 2000, An et al. 2005). This slow cycle, intrinsic to the tropical Pacific ocean-atmosphere system, interacts with the IOD (inner circle) and IOBW through changes in the Walker circulation. The IOD-ENSO and IOBW-ENSO interactions by themselves have a preferred biennial timescale. An El Niño tends to force a synchronous positive dipole and an Indian Ocean basin wide warming (e.g., Annamalai et al. 2003, with a simultaneous positive feedback; Behera and Yamagata 2003, Luo et al. 2010). This positive dipole in fall and basin-wide warming in winter both promote a transition towards a La Niña event the following year, in response to the Pacific wind variations promoted by both IOD events (I10) and IOBW (e.g. Annamalai et al 2005; Kug and Kang 2006; Ohba and Ueda 2007). The IndoPacific relations then tend to induce an ENSO-IOD-IOBW state with opposite polarities, and thus a tendency toward a biennial timescale. The IOD is however less dependent of ENSO than the IOBW, and hence brings more in terms of predictability (i.e. the role of the IOBW in the phase transition of ENSO is much more systematic than the role of the IOD).

We found no significant improvement of ENSO hindcasts when accounting for previous year's Indian monsoon. In view of this result, and because of the apparent lack of consensus of previous studies on that account, we suggest a more passive role of the Indian Monsoon in our scheme than in TBO studies such as Loschnigg et al. (2003) or Webster and Hoyos (2010). We suggest that ENSO has more influence on the Indian monsoon than the other way around. We also suggest that, while simultaneous interactions between the monsoon and IOD may exist, they are not highlighted by as significant and stable correlations as IOD-ENSO relations.

\section{Summary and Discussion}

\subsection{Summary}

I10 demonstrated that, over the 1981-2009 period, the IOD brings preconditioning information in addition to the Pacific WWV when predicting ENSO 14 months later. In the present study, we have examined the robustness and interdecadal stability of this scenario over the 18722008 period. To this end, we have constructed a historical IOD index and a WWV proxy over this period. The historical IOD index is based on a spatial regression over the whole Indian Ocean, exploiting much more SST observations than the classical DMI. The historical WWV proxy takes advantage of the linear link between the recharge process and average zonal wind stresses at low frequency, and is correlated at 0.87 with observed WWV over the recent period.

We have then used these historical indices to test I10 results over a much longer period. The tendency for the IOD events and WWV to precede ENSO events by $\sim 14$ months was strong not only during the recent period, but remained significant before the satellite era. In contrast, ENSO itself, the Indian Ocean basin-wide warming/cooling (IOBW), or the Indian Monsoon, do not provide additional predictability to following year's ENSO throughout the historical record. A 
decrease of the synchronous and lagged relationships between the IOD and ENSO and a stronger influence of WWV however appear around the sparsely sampled period of World War II.

Overall, the IOD and WWV collectively explain about 50-60\% of following year's ENSO interannual variance over the 1870's-2000's period. Both IOD and WWV independent contributions always remain significant, with a similar contribution of IOD and WWV to the ENSO skill for the early and late part of the record but a larger WWV contribution from the 1920's to the 1960's. The influences of the IOD and WWV on following year's ENSO are roughly symmetric, being significant for both phases, with negative (resp. positive) IODs and positive (negative) WWV tending to induce an El Niño (resp. La Niña) the following year. Results from a 200 years CGCM simulation display similar influence of the IOD and WWV on ENSO 14 months later, with notable decadal fluctuations.

Based on these results and analyses of biennial relations between ENSO, IOD and the Indian Monsoon, we propose a slightly revised scenario of Indo-Pacific interactions (Fig. 12), more consistent with observations (see also Tamura et al. 2011), compared to the Tropical Tropospheric Biennial Oscillation (TBO) or Webster and Hoyos (2010) frameworks. In the framework presented here, the IOD-ENSO interactions favour a biennial timescale, and interact with the slower rechargedischarge cycle intrinsic to the Pacific Ocean; but the Indian monsoon responds rather passively to the IOD-ENSO coupled system.

\subsection{Discussion and perspectives}

The present study provides additional evidence of the IOD influence on ENSO one year later. The simple statistical analyses performed in section 5.1 further suggest that the IOD brings a larger improvement to the predictive skill of following year's ENSO state than the IOBW or ENSO itself. These results complement the existing views on the Indian Ocean influence on ENSO, either through the IOD or through the IOBW (e.g. Nicholls 1984, Annamalai et al. 2005, Kug and Kang 2006, Ohba and Ueda 2007, 2009a,b, Yamanaka et al. 2009, Annamalai et al. 2010, Santoso et al. 2012). These views could well be complementary. Concerning predictability, the slowly growing IOBW is probably too much related to ENSO to bring a Pacific wind forcing independent of the ENSO cycle. The partial independency of IOD with regard to the ENSO cycle brings more predictability to ENSO hindcast one year later than the IOBW or ENSO itself. I.e. while warming in the Indian Ocean systematically tends to damp ENSO events (e.g. Santoso et al. 2012) and promotes a rapid phase transition towards the opposite ENSO phase (e.g. Annamalai et al. 2005, Kug and Kang 2006, Ohba and Ueda 2007), the IOD does not always co-occur with ENSO, and needs to be accounted for to improve the ENSO hindcasts.

Other possible influences on ENSO have been proposed. Intraseasonal Westerly Wind Bursts (WWBs) and Madden-Julian Oscillation can strongly influence El Nino onset and development (e.g. Lengaigne et al. 2004 for a review). They could even play a role in the IOD influence on El Nino onset (Izumo et al. 2010a,b). Mid-latitude forcing (Vimont et al. 2003, Chang et al. 2007, Terray 2011) is potentially another powerful ENSO precursor in boreal spring. The tropical Atlantic (e.g. Rodriguez-Fonseca et al. 2009, Jansen et al. 2009, Ding et al. 2011) might also have an influence on El Nino mature phase. It seems important to better understand if these influences are independent, or part of a larger picture.

Concerning the hindcast model constructed with $\mathrm{IOD}_{\text {hist }}$ and $\mathrm{WWV}_{\text {hist }}$, we should also remark that, in a real forecast exercise, the 7 years high-pass and 2-7 years band-pass filters (cf. sections 2.2 and 3.2) can not be used, as they use the months/years after November $30^{\text {th }}$ (the date for SON averages, from which real statistical forecasts could start). One way to overcome this issue is for example to use indices that are "backward high-pass filtered", by removing their 3 last years mean, and for the $\mathrm{WWV}_{\text {hist }}$ to also use a "backward low-pass filter" by averaging WWV hist over JJASON. 
When using such filter, the correlation skill over the $1872-2008$ period remains high, 0.66 , close to 0.72 .

An interesting perspective is the potential improvement of global seasonal forecasts at a $\sim 0.5$ to $\sim 1.5$ year lead. Fig. 13 gives a simple illustration of this potential. Fig. 13a shows the well-known global impacts of ENSO through teleconnections on land precipitation and sea level pressure (SLP; from ship observations or 20CR reanalysis), here shown in boreal winter from historical data from 1901. Hence, the ENSO estimate based on previous year's $\mathrm{IOD}_{\text {hist }}$ and $\mathrm{WWV}_{\text {hist }}$ has a significant skill to forecast following year's rainfall, SLP (Fig. 13b) and SST (not shown) in large areas of the tropics, as well as at higher latitudes, in regions influenced by the tropical Indo-Pacific through teleconnections, including north, central and south America, Australia, Indonesia, India, south-east Asia and China, eastern and southern Africa (e.g. Philander 1990, Trenberth et al. 1998).

The scenario for the IOD influence on the following year's ENSO proposed in this study relies on observational analysis, some modelling experiments and statistical analyses that leave some issues. The mechanisms for the apparently robust IOD influence need to be better understood by other sensitivity experiments with a variety of coupled models capturing the complexity of the ocean-atmosphere interactions at stake following the IOD demise.

Acknowledgements: We thank Dr. Sébastien Masson and Dr. Swadhin Behera for constructive comments on this paper. We would like to thank Dr. Lucia Bunge for sending us the ENSO historical indices of Bunge and Clarke (2009), as well as Dr. Tomoki Tozuka, Dr. Pascal Oettli, Dr. Sophie Cravatte, Dr. Caroline Ummenhofer, Dr. Pascal Terray, Hugo Dayan and Chloe Prodhomme for their help and fruitful discussions. We would like to thank Dr Julie Arblaster for her constructive comments. The first author would like to thank Pr. Toshio Yamagata and his colleagues at the University of Tokyo, especially Miss Junko Moriyama, for their hospitality and help during his stay there. The first author was funded by the University of Tokyo (partly through the SATREPS JICA/JST program) and now by the Institut de Recherche pour le Développement (IRD). Matthieu Lengaigne and Jérôme Vialard are funded by IRD. Matthieu Lengaigne gratefully acknowledges the National Institute of Oceanography (NIO, Goa, India) for hosting him during this work. Support for the 20CR project is provided by the U.S. DOE INCITE program, and BER, and by the NOAA Climate Program Office. Also, the NOAA and IRI data libraries were used for this study. The $\mathrm{IOD}_{\text {hist }}$ and $\mathrm{WWV}_{\text {hist }}$ historical indices constructed here are available at http://www.locean-ipsl.upmc.fr/ Takeshi-Izumo/data.html. 


\section{References}

Abram, N.J., M. K. Gagan, J. E. Cole, W. S. Hantoro and M. Mudelsee, 2008: Recent intensification of tropical climate variability in the Indian Ocean, Nature Geoscience, 1, 849853.

Annamalai, H., R. Murtugudde, J. Potemra, S. P. Xie, P. Liu, and B. Wang, 2003: Coupled dynamics in the Indian Ocean: Spring initiation of the zonal mode. Deep-Sea Res., 50B, 23052330.

Annamalai, H., and R. Murtugudde, 2004: Role of the Indian Ocean in regional climate variability. In Earth Climate: The Ocean-Atmosphere Interaction, C. Wang, S.-P. Xie and J.A. Carton (eds.), AGU Geophysical Monograph, 147, 213-246.

Annamalai, H., Xie, S.-P., McCreary, J.-P. \& Murtugudde, R. Impact of Indian Ocean sea surface temperature on developing El Niño. J. Clim. 18, 302-319 (2005).

Annamalai, H., S. Kida and J. Hafner, 2010: Potential impact of the tropical Indian Ocean Indonesian Seas on El Nino characteristics. J. Climate, 23, 3933-3952.

An, Soon-Il, Bin Wang, 2000: Interdecadal Change of the Structure of the ENSO Mode and Its Impact on the ENSO Frequency*. J. Climate, 13, 2044-2055.

An, Soon-Il, William W. Hsieh, Fei-Fei Jin, 2005: A Nonlinear Analysis of the ENSO Cycle and Its Interdecadal Changes*. J. Climate, 18, 3229-3239.

Ashok K, Guan Z, Yamagata T (2001) Impact of the Indian Ocean Dipole on the relationship between the Indian Monsoon rainfall and ENSO. Geophys Res Lett 28:4499-4502

Ashok K, Guan Z, Saji NH, Yamagata T (2004) Individual and combined influences of the ENSO and Indian Ocean Dipole on the Indian summer monsoon. J Climate 17:3141-3155

Ashok, K. and Saji, N. H., 2007: On impacts of ENSO and Indian Ocean Dipole events on the subregional Indian summer monsoon rainfall, Natural Hazards, Volume 42, Number 2, pp. 273 285, doi:10.1007/s11069-006-9091-0.

Battisti, D. S., and A. C. Hirst, Interannual variability in the tropical atmosphere-ocean model: influence of the basic state, ocean geometry and nonlineary, J. Atmos. Sci., 45, 1687-1712, 1989.

Barnett, T.P., 1983: Interaction of the Monsoon and Pacific Trade Wind System at Interannual Time Scales. Part I: The Equatorial Zone. Mon. Wea. Rev., 111, 756-773.

Behera SK, Krishnan R, Yamagata T (1999) Unusual ocean-atmosphere conditions in the tropical Indian Ocean during 1994. Geophys Res Lett 26:3001-3004.

Behera, S. K., and T. Yamagata, 2003 : Influence of the Indian Ocean Dipole on the Southern Oscillation. J. Meteor. Soc. Jpn., 81 (1), 169-177.

Behera, S. K., J.-J. Luo, S. Masson, S. A. Rao, H. Sakuma, and T. Yamagata, 2006: A CGCM study on the interaction between IOD and ENSO. J. Climate, 19, 1688-1705.

Bentamy, A., Quilfen, Y., Gohin, F., Grima, N., Lenaour, M., and Servain, J.: Determination and validation of average field from ERS-1 scatterometer measurements, Global Atmos. Ocean Sys., 4, 1-29, 1996.

Bjerknes, J., Atmospheric teleconnections from the equatorial Pacific, Mon. Weather Rev., 97, 163-172, 1969.

Boschat, G., Terray, P., and S. Masson, 2012. Robustness of SST teleconnections and precursory patterns associated with the Indian Summer Monsoon Rainfall, submitted.

Brown, Jaclyn N., Alexey V. Fedorov, 2010: Estimating the Diapycnal Transport Contribution to Warm Water Volume Variations in the Tropical Pacific Ocean. J. Climate, 23, 221-237.

Bunge, L., and A. J. Clarke, 2009. A verified estimation of the El Nino index NINO3.4 since 1877. Journal of Climate, 22(14), 3979-3992.

Burgers, G., F.-F. Jin, and G. J. van Oldenborgh (2005), The simplest ENSO recharge oscillator, Geophys. Res. Lett., 32, L13706, doi:10.1029/2005GL022951. 
Chang, P., L. Zhang, R. Saravanan, D. J. Vimont, J. C. H. Chiang, L. Ji, H. Seidel, and M. K. Tippett (2007), Pacific meridional mode and El Niño-Southern Oscillation, Geophys. Res. Lett., 34, L16608, doi:10.1029/2007GL030302

Cherchi A. and A. Navarra, 2012. Influence of ENSO and of the Indian Ocean Dipole on the Indian summer monsoon variability, Clim. Dyn, accepted.

Chowdary, J. S., S.-P. Xie, H. Tokinaga, Y. M. Okumura, H. Kubota, N. C. Johnson, and X.-T. Zheng, 2012: Interdecadal variations in ENSO teleconnection to the Indo-western Pacific for 1870-2007. J. Climate 25, 1722.

Clarke, A. J., S. Van Gorder, Improving El Niño prediction using a space-time integration of IndoPacific winds and equatorial Pacific upper ocean heat content, Geophys. Res. Lett., 30(7), 1399, doi:10.1029/2002GL016673, (2003).

Clarke 2008: An introduction to the dynamics of El Nino and the Southern Oscillation, Elsevier Academic Press.

Collins, M., An, S.-I., Cai, W., Ganachaud, A., Guilyardi, E., Jin, F.-F., Jochum, M., Lengaigne, M., Power, S., Timmermann, A., Vecchi, G. and Wittenberg, A. 2010. The impact of global warming on the tropical Pacific Ocean and El Niño. Nature Geoscience 3: 391-397.

Compo GP et al. 2011. The Twentieth Century Reanalysis Project. Q. J. R. Meteorol. Soc. 137: 128. DOI:10.1002/qj.776

Ding H., N. S. Keenlyside, and M. Latif (2011): Impact of the Equatorial Atlantic on the El Niño Southern Oscillation. Climate Dynamics,

DOI: $10.1007 / \mathrm{s} 00382-011-1097-y$.

Fasullo, J. 2004, Biennial characteristics of All India rainfall. J. Clim, 17, 2972-2982.

Fedorov, A.V., 2010: Ocean Response to Wind Variations, Warm Water Volume, and Simple Models of ENSO in the Low-Frequency Approximation. J. Climate, 23, 3855-3873.

Fischer, A., P. Terray, E. Guilyardi, S. Gualdi, and P. Delecluse, 2005: Two independent triggers for the Indian Ocean Dipole/Zonal Mode in a coupled GCM, J. Clim., 18, 3428 - 3449

Gadgil S, Vinayachandran PN, Francis PA, Gadgil S (2004) Extremes of the Indian summer monsoon rainfall, ENSO, and equatorial Indian Ocean oscillation. Geophys Res Lett 31:1821, doi:10.1029/2004GL019733

Gershunov A, Schneider N, Barnett T (2001) Low frequency modulation of the ENSO-monsoon rainfall relationship: signal or noise? J Climate 14:2486-2492284 Nat Hazards (2007) 42:273285

Goddard, L. and S. G. H. Philander, 2000. The energetics of El Nino and La Nina. J. Climate, 13: 1496-1516.

Hoerling, M.P., A. Kumar, and T.-Y. Xu, 2001: Robustness of the nonlinear atmospheric response to opposite phases of ENSO. J. Climate, 14, 1277-1293.

Huffman GJ, Adler RF, Arkin PA, Chang A, Ferraro R, Gruber A, Janowiak J, Joyce RJ, McNab A, Rudolf B, Schneider U, Xie P, 1997: The global precipitation climatology project (GPCP) combined precipitation data set. Bull Am Meteor Soc., 78, 5-20

Izumo, T., C. de Boyer Montégut, J.-J. Luo, S. K. Behera, S. Masson, and T. Yamagata, 2008: The role of the western Arabian Sea upwelling in Indian monsoon rainfall variability, J. Climate, 21, 5603-5623.

Izumo, T., J. Vialard, M. Lengaigne, C. de Boyer Montégut, S. K. Behera, J-J. Luo, S. Cravatte, S. Masson, and T. Yamagata, 2010a: Influence of the Indian Ocean Dipole on following year's El Niño, Nature Geoscience, 3, 168-172.

Izumo, T., Masson S., Vialard J., C. de Boyer Montegut, S. K. Behera, G. Madec, K. Takahashi and T. Yamagata, 2010b: Low and high frequency Madden-Julian Oscillations in Austral Summer Interannual variations. Climate Dyamics, 35, 669-683.

Jin FF (1997a) An equatorial ocean recharge paradigm for ENSO. Part I: conceptual model. J Atmos Sci 54:811-829 
Jin FF (1997b) An equatorial ocean recharge paradigm for ENSO. Part II: A Stripped-Down Coupled Model. J Atmos Sci 54: 830-847.

Kanamitsu, M., Ebisuzaki, W., Woollen, J., Yang, S.-K., Hnilo, J. J., Fiorino, M., and Potter, G. L., 2002: NCEP-DOE AMIP-II reanalysis. Bull. Amer. Meteor. Soc., 83, 1631-1643.

Kirtman, B. P., and J. Shukla, 2000: On the influence of the Indian summer Monsoon on ENSO. Quart. J. Roy. Meteor.. Soc., 126, 213-239.

Klein, S. A., B. J. Soden, and N. C. Lau, 1999: Remote sea surface temperature variations during ENSO: Evidence for a tropical atmospheric bridge. J. Climate, 12, 917-932.

Krishna Kumar KK, Rajagopalan KB, Cane MA (1999) On the weakening relationship between the Indian monsoon and ENSO. Science 284:2156-2159

Krishnamurti, T.N., Chu S.H., Iglesias W., 1986: On The Sea-Level Pressure Of The Southern Oscillation, Archives for meteorology, geophysics, and bioclimatology. Series A, Meteorology and geophysics, 34, 384-425.

Krishnan R, Swapna P (2009) Significance influence of the boreal summer monsoon flow on the Indian Ocean response during dipole events. J Clim 22:5611-563410.

Kug, J.-S., and I.-S. Kang, 2006: Interactive feedback between the Indian Ocean and ENSO. J. Climate, 19, 1784-1801.

Kug, J-S., T. Li, S-I. An, I-S. Kang, J-J. Luo, S. Masson, and T. Yamagata, 2006: Role of the ENSO-Indian Ocean coupling on ENSO variability in a coupled GCM. Geophys. Res. Lett., 33, L09710. doi:10.1029/2005GL024916.

Kug, J.-S. and Y. -G. Ham, 2012 : Indian Ocean feedback to the ENSO transition in a multi-model ensemble, J. Clim., 25, 6942-6957. DOI 10.1175/JCLI-D-12-00078.1

Leloup J.A., Z. Lachkar, JP Boulanger and S. Thiria 2007, Detecting decadal changes in ENSO using neural networks, Clim Dyn. DOI: 10.1007/s00382-006-0173-1

Lengaigne, M., J.-P. Boulanger, C. Menkes, P. Delecluse, \& J. Slingo, 2004: Westerly wind events in the tropical Pacific and their influence on the coupled ocean-atmosphere system: A review, in Earth Climate: The Ocean-Atmosphere Interaction, Geophys. Monogr. Ser., 147, 49- 69, AGU, Washington, D. C.

Lengaigne M, Haussmann U, Madec G, Menkes C, Vialard J, Molines JM (2011) Mechanisms controlling warm water volume interannual variations in the equatorial Pacific: diabatic versus adiabatic processes. Clim Dyn, in press.

Liebmann, B., and C. A. Smith, 1996: Description of a complete (interpolated) outgoing longwave radiation dataset. Bull. Amer. Meteor. Soc., 77, 1275-1277.

Loschnigg, J., G.A. Meehl, P.J. Webster, J.M. Arblaster, and G.P. Compo, 2003: The Asian monsoon, the tropospheric biennial oscillationand the Indian Ocean Dipole in the NCAR CSM. J.Climate, 16,2138-2158.

Luo, J.-J., S. Masson, E. Roeckner, G. Madec and T. Yamagata, 2005: Reducing climatology bias in an ocean-atmosphere CGCM with improved coupling physics. J. Climate, 18, 2344-2360.

Luo, J.-J., S. Behera, Y. Masumoto, H. Sakuma, and T. Yamagata, 2008: Successful prediction of the consecutive IOD in 2006 and 2007. Geophys. Res. Lett., 35, L14S02, doi:10.1029/2007GL032793.

Luo, J.-J., R. Zhang, S. Behera, Y. Masumoto, F.-F. Jin, R. Lukas, and T. Yamagata, 2010: Interaction between El Niño and extreme Indian Ocean Dipole. J. Climate, 23, 726-742.

Madec, G., P. Delecluse, M. Imbard and C. Levy, 1998: OPA 8.1 Ocean General Circulation Model reference manual. Notes du pôle de modélisation de l'IPSL 11, 91pp., available at http://www.lodyc.jussieu.fr/opa.

Masson, S. et al., 2005: Impact of barrier layer on winter-spring variability of the southeastern Arabian Sea, Geophys. Res. Lett., 32, L07703, doi:10.1029/2004GL021980.

Meehl, G. A., 1987: The annual cycle and interannual variability in the tropical Pacific and Indian Ocean region. Mon. Wea. Rev., 115, 27-50 
Meehl, G.A., J.M. Arblaster, and J. Loschnigg, 2003: Coupled ocean-atmosphere Dynamical processes in the tropical Indian and Pacific Ocean regions and the TBO. J. Climate,16,21382158.

Meehl, G. A., and J. M. Arblaster, 2011: Decadal variability of Asian-Australian monsoon-ENSOTBO relationships. J. Climate, 24, 4925-4940.

Meinen, C. S., and M. J. McPhaden, 2000: Observations of warm water volume changes in the equatorial Pacific and their relationship to El Niño and La Niña. J. Climate, 13, 3551-3559

Murtugudde, R., and A. J. Busalacchi, 1999: Interannual variability of the dynamics and thermodynamics of the tropical Indian Ocean. J. Climate, 12, 2300-2326.

Murtugudde, R., J. P. McCreary, and A. J. Busalacchi, 2000: Oceanic processes associated with anomalous events in the Indian Ocean with relevance to 1997-1998. J. Geophys. Res., 105, $3295-3306$.

Neelin, J. D., D. S. Battisti, A. C. Hirst, F.-F. Jin, Y. Wakata, T. Yamagata, and S. E. Zebiak, 1998: ENSO theory. J. Geophys. Res., 103, 14 261-14 290.

Nicholls, N., 1984: The Southern Oscillation and Indonesian sea surface temperature. Mon. Wea. Rev., 112, 424-432.

Ohba, M. and Ueda, H. , 2005: Basin-wide warming in the equatorial Indian Ocean associated with El Nino. Scientific Online Letters on the Atmosphere,1, 089-092, doi: 10.2151/sola.

Ohba, M. and H. Ueda, 2007: An impact of SST anomalies in the Indian Ocean in acceleration of the El Niño to La Niña transition. J. Meteor. Soc. Japan,85,335-348.

Ohba, M., and H. Ueda, 2009a: Role of nonlinear atmospheric response to SST on the asymmetric transition process of ENSO. J. Climate, 22, 177-192.

Ohba, M., and H. Ueda, 2009b: Seasonally different response of the Indian Ocean to the remote forcing of El Niño: Linking the dynamics and thermodynamics. SOLA, 5, 176-179, doi:10.2151/sola.2009-045.

Ohba, M., D. Nohara, and H. Ueda, 2010: Simulation of asymmetric ENSO transition in WCRP CMIP3 multi-model experiments. J. Climate

Ohba, M. and M. Watanabe. (2012) Role of the Indo-Pacific Interbasin Coupling in Predicting Asymmetric ENSO Transition and Duration. Journal of Climate 25:9, 3321-3335.

Okumura, Yuko M., Clara Deser, 2010: Asymmetry in the Duration of El Niño and La Niña. J. Climate, 23, 5826-5843.

Okumura, Yuko M., Masamichi Ohba, Clara Deser, Hiroaki Ueda, 2011: A Proposed Mechanism for the Asymmetric Duration of El Niño and La Niña. J. Climate, 24, 3822-3829.

Oldenborgh, G.J. van and G. Burgers, Searching for decadal variations in ENSO precipitation teleconnections. Geophys. Res. Lett., 2005, 32, 15, L15701

Parthasarathy, B., A. A. Munot, and D. R. Kothawale, 1994: All India monthly and seasonal rainfall series-1871-1993. Theor. Appl. Climatol., 49, 217-224.

Picaut, J., F. Masia, and Y. du Penhoat, 1997: An advective-reflective conceptual model for the oscillatory nature of the ENSO, Science, 277, 663-666.

Rayner, N. A.; Parker, D. E.; Horton, E. B.; Folland, C. K.; Alexander, L. V.; Rowell, D. P.; Kent, E. C.; Kaplan, A. (2003) Global analyses of sea surface temperature, sea ice, and night marine air temperature since the late nineteenth century J. Geophys. Res.Vol. 108, No. D14, 4407 10.1029/2002JD002670

Rayner, N.A., P.Brohan, D.E.Parker, C.K.Folland, J.J.Kennedy, M.Vanicek, T.Ansell and S.F.B.Tett, 2006: Improved analyses of changes and uncertainties in sea surface temperature measured in situ since the mid-nineteenth century: the HadSST2 data set. J. Clim. 19(3) pp. 446-469.

Reverdin G., D. Cadet, and D. Gutzler, 1986: Interannual displacements of convection and surface circulation over the equatorial Indian Ocean. Quart. J. Roy. Meteor. Soc., 112, 43-46. 
Reynolds, R. W., N. A. Rayner, T.M. Smith, D. C. Stokes and W. Wang, 2002: An improved in situ and satellite SST analysis for climate. J. Clim., 15, 1609-1625.

Rodriguez-Fonseca B., I. Polo, J. Garcia-Serrano, T. Losada, E. Mohino, C. R. Mechoso and F. Kucharski, (2009): Are the Atlantic Ninos enhancing Pacific ENSO events in recent decades?. Geophys. Res. Lett., vol. 36, L20705, doi:10.1029/2009GL040048

Roeckner, E. and Coauthors., 1996: The atmospheric general circulation model ECHAM-4: Model description and simulation of present-day climate. Max-Planck-Institut für Meteorologie Rep., 218, 90 pp.

Rudolf, B., et al. (2010): GPCC Status Report December 2010 (On the most recent gridded global data set issued in fall 2010 by the Global Precipitation Climatology Centre (GPCC)).

Saji, N. H., B. N. Goswami, P. N. Vinayachandran \& T. Yamagata, 1999: A dipole mode in the tropical Indian Ocean. Nature 401, 360-363.

Santoso et al. 2012

Schopf P.S. and M.J. Suarez, 1988: Vacillations in a coupled ocean-atmosphere model. J Atmos Sci., , 549-566.

Smith, N.R., 1995: An improved system for tropical ocean sub-surface temperature analyses. $J$. Atmos. Oceanic Technol., 12, 850-870.

Smith, Thomas M., Richard W. Reynolds, Thomas C. Peterson, Jay Lawrimore, 2008: Improvements to NOAA's Historical Merged Land-Ocean Surface Temperature Analysis (1880-2006). J. Climate, 21, 2283-2296. doi: 10.1175/2007JCLI2100.1

Tamura, T., T. Koike, A. Yamamoto, M. Yasukawa and M. Kitsuregawa; Contrasting Impacts of the Indian Ocean Dipole and ENSO on the Tropospheric Biennial Oscillation, SOLA, Vol. 7, pp.13-16 (2011)

Terray P, Dominiak S, Delecluse P (2005) Role of the southern Indian Ocean in the transitions of the monsoon-ENSO system during recent decades. Clim Dyn 24:169-195, DOI 10.1007/s00382-004-0480-3.

Terray P, Dominiak S (2005) Indian Ocean Sea Surface Temperature and El Nino-Southern Oscillation: a new perspective. J Clim 18:1351-1368.

Trenberth, K. E., Branstator, G. W., Karoly, D., Kumar, A., Lau, N.-C. and Ropelewski, C. Progress during TOGA in understanding and modeling global teleconnections associated with tropical sea surface temperatures. J. Geophy. Res. 103, 14291-14324, 1998.

Ummenhofer CC, England MH, McIntosh PC, Meyers GA, Pook MJ, Risbey JS, Sen Gupta A, and Taschetto AS. (2009). What causes Southeast Australia's worst droughts? Geophysical Research Letters, 36, L04706, doi:10.1029/2008GL036801.

Ummenhofer CC, Sen Gupta A, Li Y, Taschetto AS, and England MH. (2011). Multi-decadal modulation of the El Nino-Indian monsoon relationship by Indian Ocean variability. Environmental Research Letters, 6, 034006, doi:10.1088/1748-9326/6/3/034006.

Vialard, J., C. Menkes, J.-P. Boulanger, P. Delecluse, E. Guilyardi, M.J. McPhaden and G. Madec, 2001: A model study of oceanic mechanisms affecting equatorial Pacific sea surface temperature during the 1997-98 El Niño, J. Phys. Oceanogr., 31,1649-1675.

Vimont, Daniel J., John M. Wallace, David S. Battisti, 2003: The Seasonal Footprinting Mechanism in the Pacific: Implications for ENSO. J. Climate, 16, 2668-2675.

Walker, G.T., 1924: World Weather IX. Mem. Indian Meteor. Dept., 24, 275-332.

Wang, C., and J. Picaut, 2004: Understanding ENSO physics - A review. In: Earth's Climate: The Ocean-Atmosphere Interaction. C. Wang, S.-P. Xie, and J. A. Carton, Eds., AGU Geophysical Monograph Series, 147:21-48.

Watanabe, M. and F.-F. Jin, 2002: Role of Indian Ocean warming in the development of Philippine Sea anticyclone during ENSO. Geophys. Res. Lett., 29 (10), 1478, doi:10.1029/2001GL014318.

Watanabe, M., 2008a: Two regimes of the equatorial warm pool. Part I: A simple tropical 
climate model. J. Climate, 21, 3533-3544.

Watanabe, M., 2008b: Two Regimes of the Equatorial Warm Pool. Part II: Hybrid Coupled GCM Experiments. J. Climate, 21, 3545-3560.

Webster PJ, Moore A, Loschnigg J, Leban M (1999) Coupled dynamics in the Indian Ocean during 1997-1998. Nature 401:356-360

Webster, P. J., C. Clark, G. Cherikova, J. Fasullo, W. Han, J. Loschnigg, and K. Sahami, 2002: The Monsoon as a self-regulating coupled ocean-atmosphere system. Meteorology at the Millennium. International Geophysical Series, Volume 83, Academic press, 198-219.

Webster, P. J., C. D. Hoyos, 2010: Beyond the spring barrier?, Nat. Geo., 3, 152-153, doi:10.1038/ngeo800

$\mathrm{Wu}, \mathrm{R}$., and B. P. Kirtman (2004), Understanding the impacts of the Indian Ocean on ENSO variability in a coupled GCM, J. Clim., 17, $4019-4031$.

Wyrtki, K., 1975: El Niño--the dynamic response of the equatorial Pacific Ocean to atmospheric forcing. J. Phys. Oceanogr., 5 (4), 572-584.

Wyrtki K (1985) Water displacements in the Pacific and the genesis of El Niño cycles. J Geophys Res 90:7129-7132

Xavier P. K., C. Marzin and B. N. Goswami (2007) An objective definition of the Indian summer monsoon season and a new perspective on ENSO-monsoon relationship, Quarterly Journal of Royal Meteorological Society, 133, 749-764.

Xie, S.-P., K. Hu, J. Hafner, H. Tokinaga, Y. Du, G. Huang, and T. Sampe (2009), Indian Ocean capacitor effect on Indo-western Pacific climate during the summer following El Nino, J. Clim.,

Yamagata T, Behera SK, Luo J-J, Masson S, Jury MR, Rao SA (2004) The coupled oceanatmosphere variability in the tropical Indian Ocean. Earth's climate: the ocean-atmosphere interaction. Geophys Monogr 147:189-211

Yamanaka, G., T. Yasuda, Y. Fujii, and S. Matsumoto (2009), Rapid termination of the 2006 El Niño and its relation to the Indian Ocean, Geophys. Res. Lett., 36, L07702, doi:10.1029/2009GL037298.

Yasunari T, 1985: Zonally Propagating Modes Of The Global East-West Circulation Associated With The Southern Oscillation, J. Met. Soc. Japan, 63, 1013-1029.

$\mathrm{Yu}, \mathrm{J}-\mathrm{Y}, \mathrm{CR}$ Mechoso, JC McWilliams and A Arakawa (2002), Impact of the Indian Ocean on the ENSO cycle, Geophys. Res. Lett., 29, 1204, doi:10.1029/2001GL014098.

Yu, J-Y (2005), Enhancement of ENSO's persistence barrier by biennial variability in a coupled atmosphere-ocean general circulation model, Geophys. Res. Lett., 32, L13707, doi:10.1029/2005GL023406. 


\section{Table}

Table 1: Hindcast skill of ENSO peak (Niño3.4 $4_{\text {hist }}$ in NDJ0), when predicted using a regional SST index at its peak season $\left(2^{\text {nd }}\right.$ column $)$, the $\mathrm{WWV}_{\text {hist }}$ at the same season $\left(3^{\text {rd }}\right.$ column $)$ or $\mathrm{WWV}_{\text {hist }}$ combined to the SST index ( $4^{\text {th }}$ column). The $5^{\text {th }}$ column gives the significance level of the improvement in skill from the hindcast based on $\mathrm{WWV}_{\text {hist }}$ alone $\left(3^{\text {rd }}\right.$ column $)$ to the multivariate hindcast $\left(4^{\text {th }}\right.$ column). NDJ-1 means Nov-Dec(yr-1)-Jan(yr0). All the skills in this table are computed over the 1872-2008 period.

\begin{tabular}{|l|c|c|c|c|}
\hline Predictor (season): & $\begin{array}{c}\text { Skill if } \\
\text { predictor } \\
\text { "x" alone }\end{array}$ & $\begin{array}{c}\text { Skill if WWV } \\
\text { alone }\end{array}$ & $\begin{array}{c}\text { Skill of multiple } \\
\text { regression based } \\
\text { on WWV+"x" }\end{array}$ & $\begin{array}{c}\text { Significance } \\
\text { of the } \\
\text { increase in } \\
\text { skill }\end{array}$ \\
\hline IOD $_{\text {hist }}$ (SON-1) & 0.44 & 0.59 & $\mathbf{0 . 7 2}$ & $\mathbf{9 8 \%}$ \\
\hline IOBW (JFM 0) & 0.32 & 0.59 & 0.62 & $<60 \%$ \\
\hline Nino3.4 $4_{\text {hist }}$ (NDJ-1) & 0.14 & 0.61 & 0.63 & $<60 \%$ \\
\hline AIR (JJAS-1) & 0.11 & 0.53 & 0.58 & $<60 \%$ \\
\hline IOD $_{\text {hist }}$ (JJAS-1) & 0.44 & 0.53 & $\mathbf{0 . 6 6}$ & $\mathbf{9 7 \%}$ \\
\hline
\end{tabular}




\section{Figures}

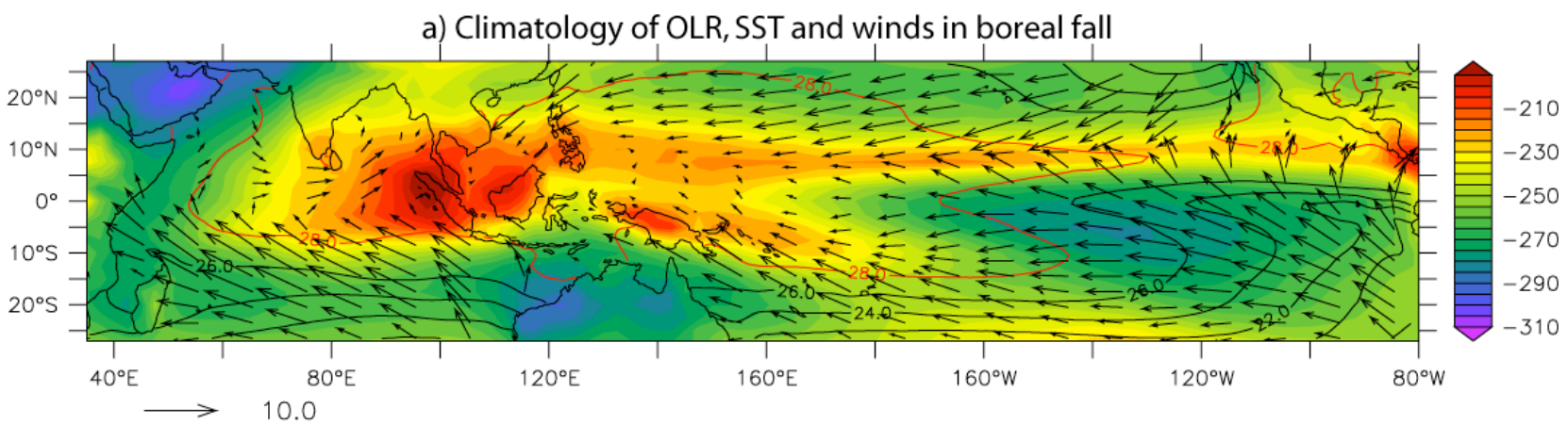

b) Sensitivity of precipitation to local SST in fall

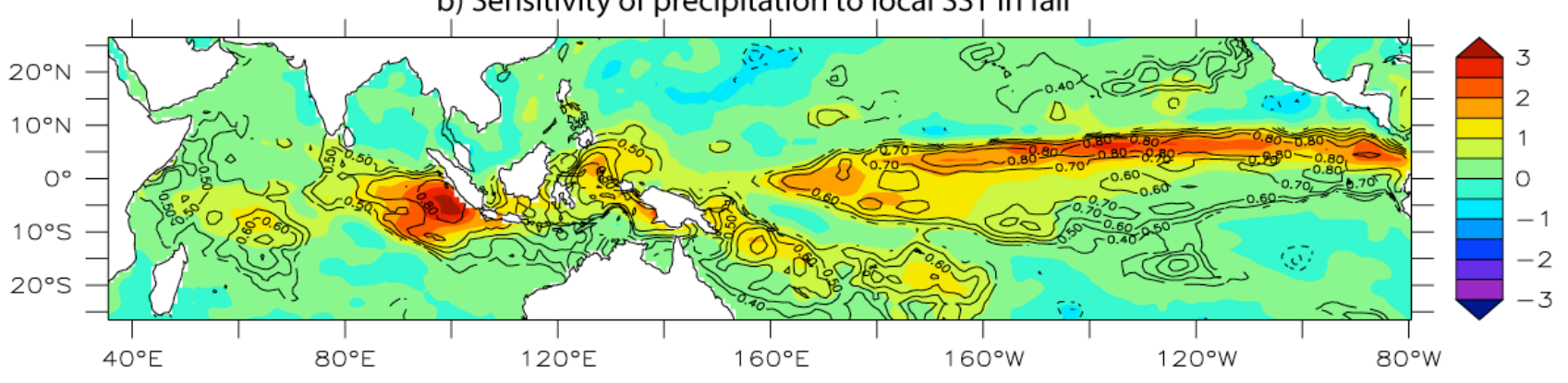

c) OLR and SST in fall regressed on Nino3.4 SST

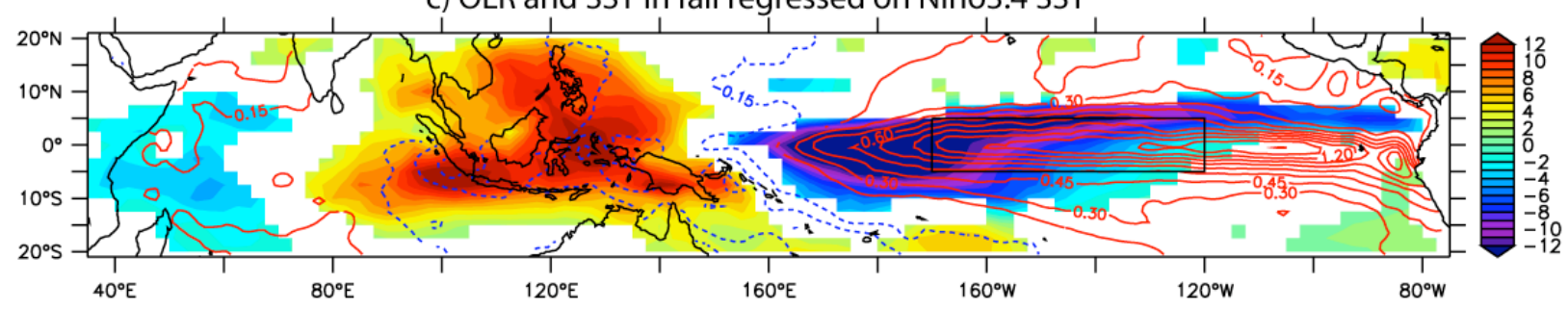

d) OLR and SST in fall of the preceding year

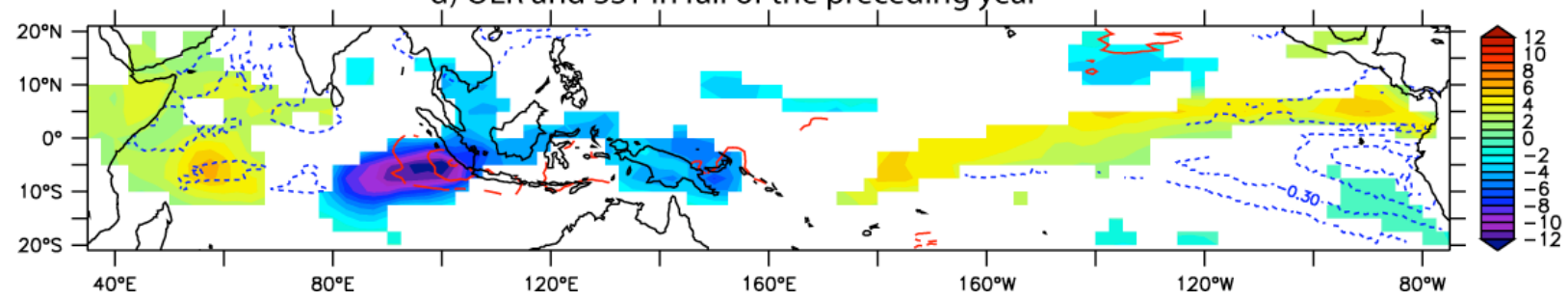

Fig. 1: a) Climatology of OLR (i.e. deep convection, color, W.m ${ }^{-2}$ ), SST (OISSTv2, contours, red for the $28^{\circ} \mathrm{C}$ isotherm showing the warm pool boundaries) and winds (ERS, vectors, $\mathrm{m} / \mathrm{s}$ ) in autumn (SON). b) Sensitivity of local precipitation to local SST for autumn mean, as inferred from the regression of precipitation (GPCP, color, $\mathrm{mm} / \mathrm{d}$ per one standard deviation of local SST) onto SST, and correlation (black contours, when significant at the 90\% level, 1981-2009). c) Anomalies of OLR (color, W.m ${ }^{-2}$ ) and SST (red lines/blue dashes for positive/negative values, ${ }^{\circ} \mathrm{C}$ ) in autumn during an El Niño year (year 0). Anomalies inferred from the regression of OLR or SST on Niño3.4 SST (black box) over the period of 1981-2009. Only signals significant at the $90 \%$ level are plotted. d) As in c, but for the results during the preceding year's autumn (SON of year -1). 
a) Density of in-situ observations

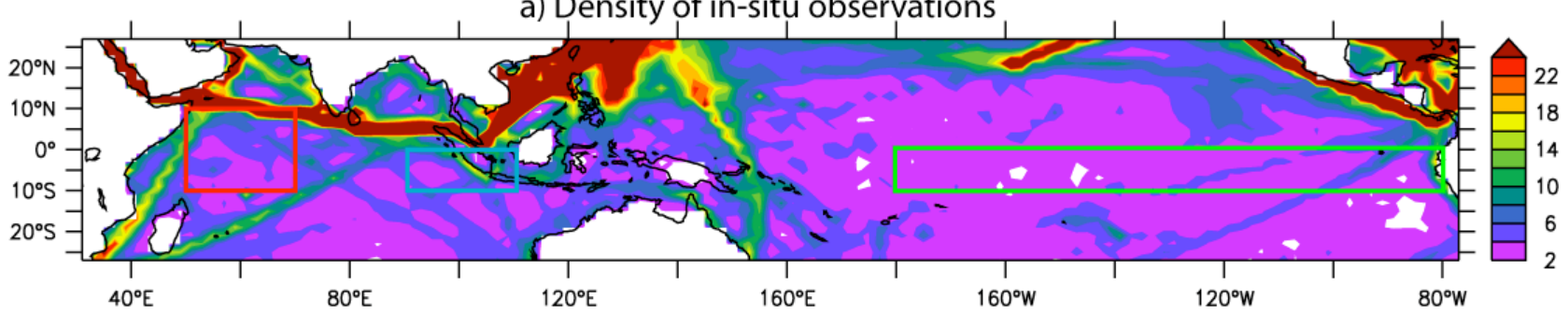

b) Number of observations for each index (sqrt(N))

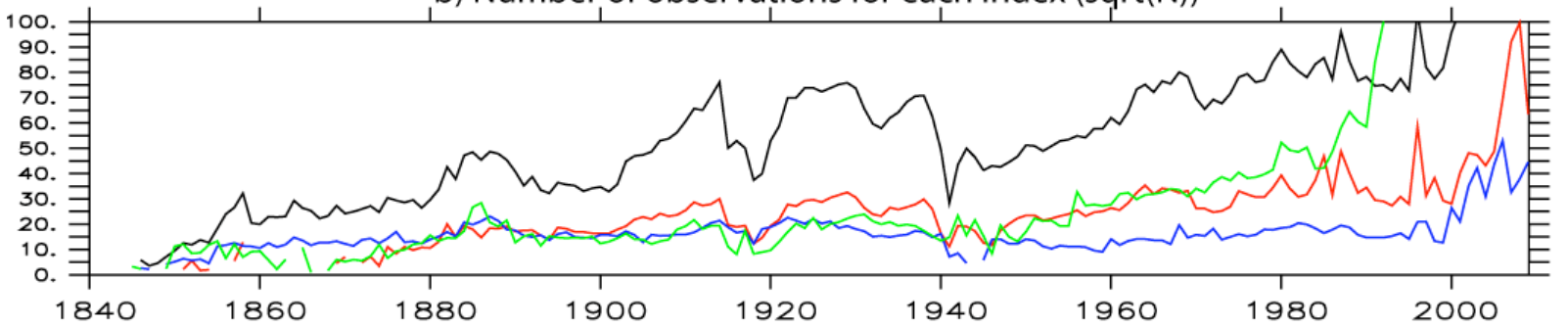

c) Measurement and sampling error for each index

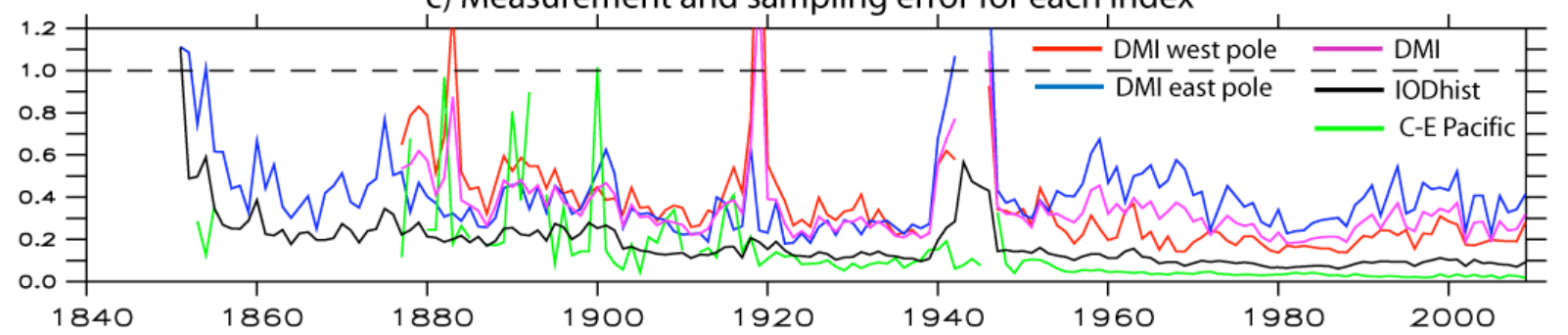

Figure 2: Historical data density and uncertainties. a) Map of the density of SST in situ observations (number of data per month and per $2^{\circ}$ by $2^{\circ}$ grid box), for autumn (SON), for the 18701979 period (from ICOADS product). The boxes are shown for DMI poles in red and blue, and for central-eastern equatorial Pacific in green. b) Evolution of the total number of SST observations per month in each box (unit here: square root of the number of observations per month, as the uncertainties will be inversely proportional to this square root): the DMI western pole (red, $50^{\circ} \mathrm{E}-$ $70^{\circ} \mathrm{E}, 10^{\circ} \mathrm{S}-10^{\circ} \mathrm{N}$ ), the DMI eastern pole (blue, $90^{\circ} \mathrm{E}-110^{\circ} \mathrm{E}, 10^{\circ} \mathrm{S}-0^{\circ}$ ), the whole tropical Indian Ocean used for the computation of the $\mathrm{IOD}_{\text {hist }}$ index (black, $35^{\circ} \mathrm{E}-121^{\circ} \mathrm{E}, 25^{\circ} \mathrm{N}-25^{\circ} \mathrm{S}$ ) in $\mathrm{SON}$, and the central-eastern equatorial Pacific (green, $180^{\circ}-80^{\circ} \mathrm{W}, 5^{\circ} \mathrm{N}-5^{\circ} \mathrm{N}$ ) in NDJ. c) Measurement and sampling error (i.e. uncorrelated spatio-temporally, from HadSST2) for each normalised index. The horizontal dashed line corresponds to a $100 \%$ uncertainty on index interannual variability. 


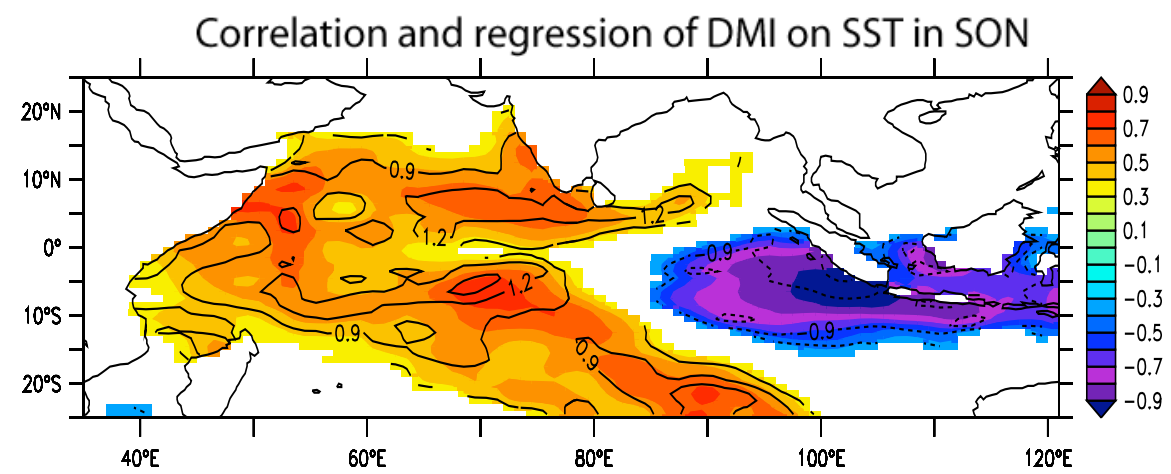

Figure 3: Correlation (color) and regression coefficient (contours, ${ }^{\circ} \mathrm{C}$ of DMI per one standard deviation of SST) of DMI on SST in SON (NOAA OISSTv2, 1981-2009). This regression is used to define $\mathrm{IOD}_{\text {hist }}$. 
WWVist compared to observed WWV

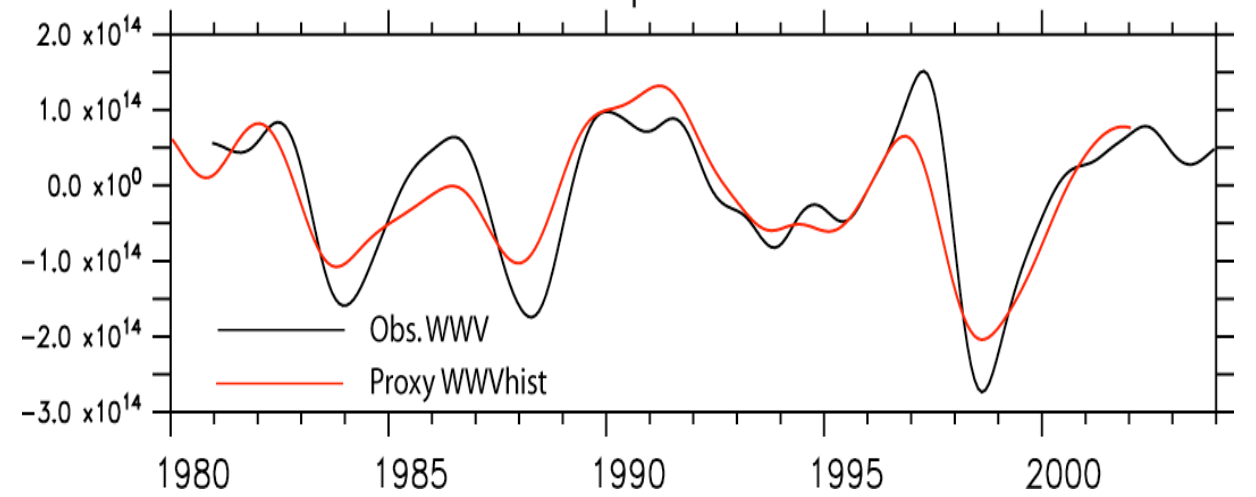

Fig. 4: Comparison of the reconstructed $W_{W V}$ hist $($ red) with the observed WWV (black, with a 1year low-pass filter as for $\mathrm{WWV}_{\text {hist }}$; correl. $=0.87$; regression coefficient $=6.1 \times 10^{8} \mathrm{~m}^{5} \mathrm{~N}^{-1} \mathrm{~s}^{-1}$ ). 
a) simultaneous correlations with ENSO



b) one year-lead correlations

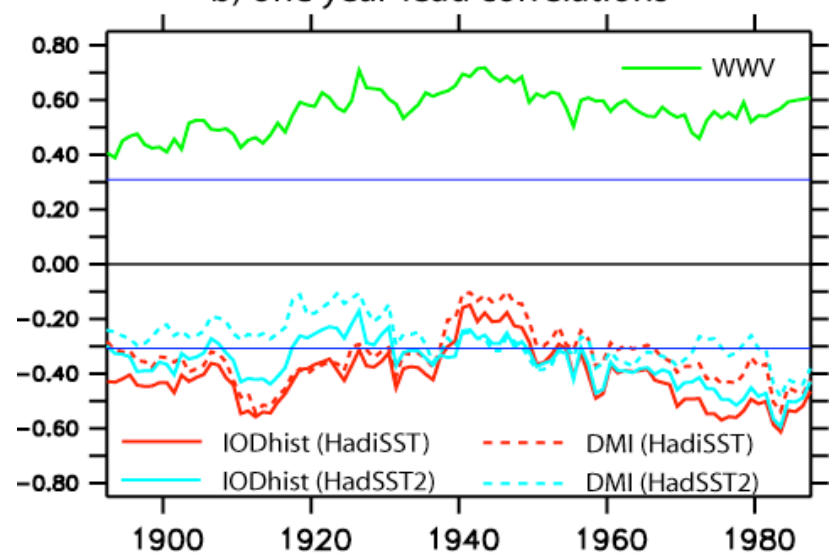

c) standard deviations

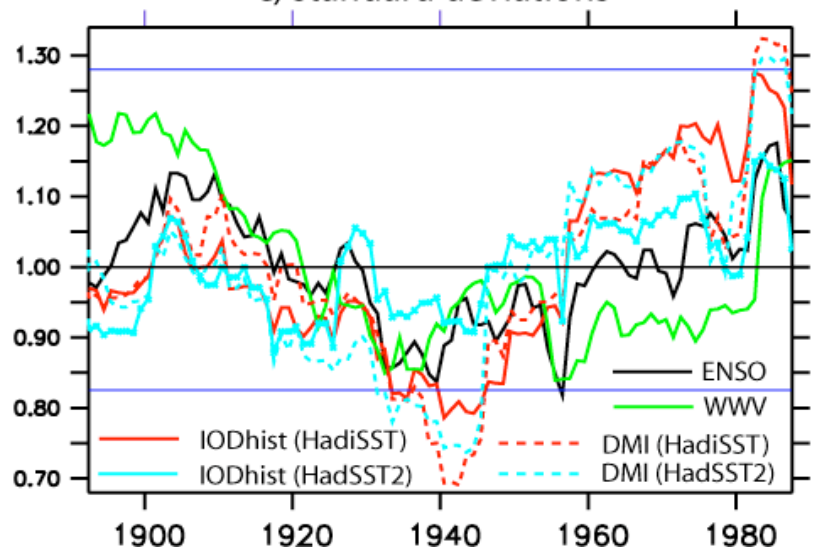

Fig. 5: Interdecadal variations of IOD/WWV - ENSO relationships. a) Simultaneous correlation of IOD with ENSO (red curves when using HadiSST for IOD, blue curves with HadSST2; continuous lines for $\mathrm{IOD}_{\text {hist }}$, dashed lines for DMI). b) As in a, but for the one-year lead correlations of IOD or WWV with following year's ENSO. 90\% significance level shown as thin horizontal blue lines for both panels a and b. c) Standard deviations (normalised by their means) of ENSO (black), IOD (red/blue) and $\mathrm{WWV}_{\text {hist }}$ (green), statistically different from their mean if out of the $90 \%$ confidence interval indicated by the thin horizontal blue lines. Statistics calculated on 30 years sliding windows, the horizontal axis showing window central date. 


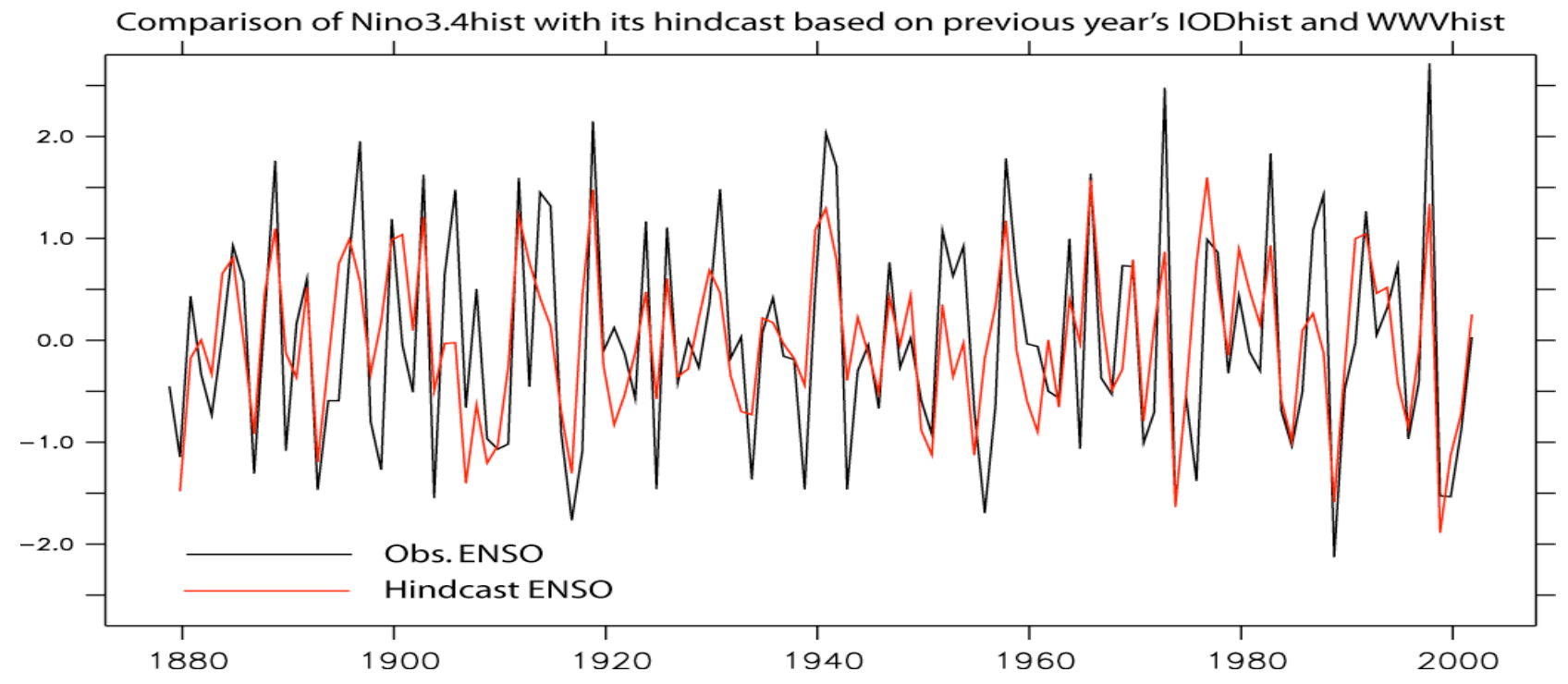

Fig. 6: ENSO (black, Nino3.4 $4_{\text {hist }}$ NDJ) compared to its one-year lead estimate (red, correl. $=0.72$ ) based on a multiple linear regression using $\mathrm{IOD}_{\text {hist }}(\mathrm{SON})$ and $\mathrm{WWV}_{\text {hist }}(\mathrm{SON})$ of previous year. Using the DMI instead of $\mathrm{IOD}_{\text {hist }}$ leads to a similar skill (0.70). 

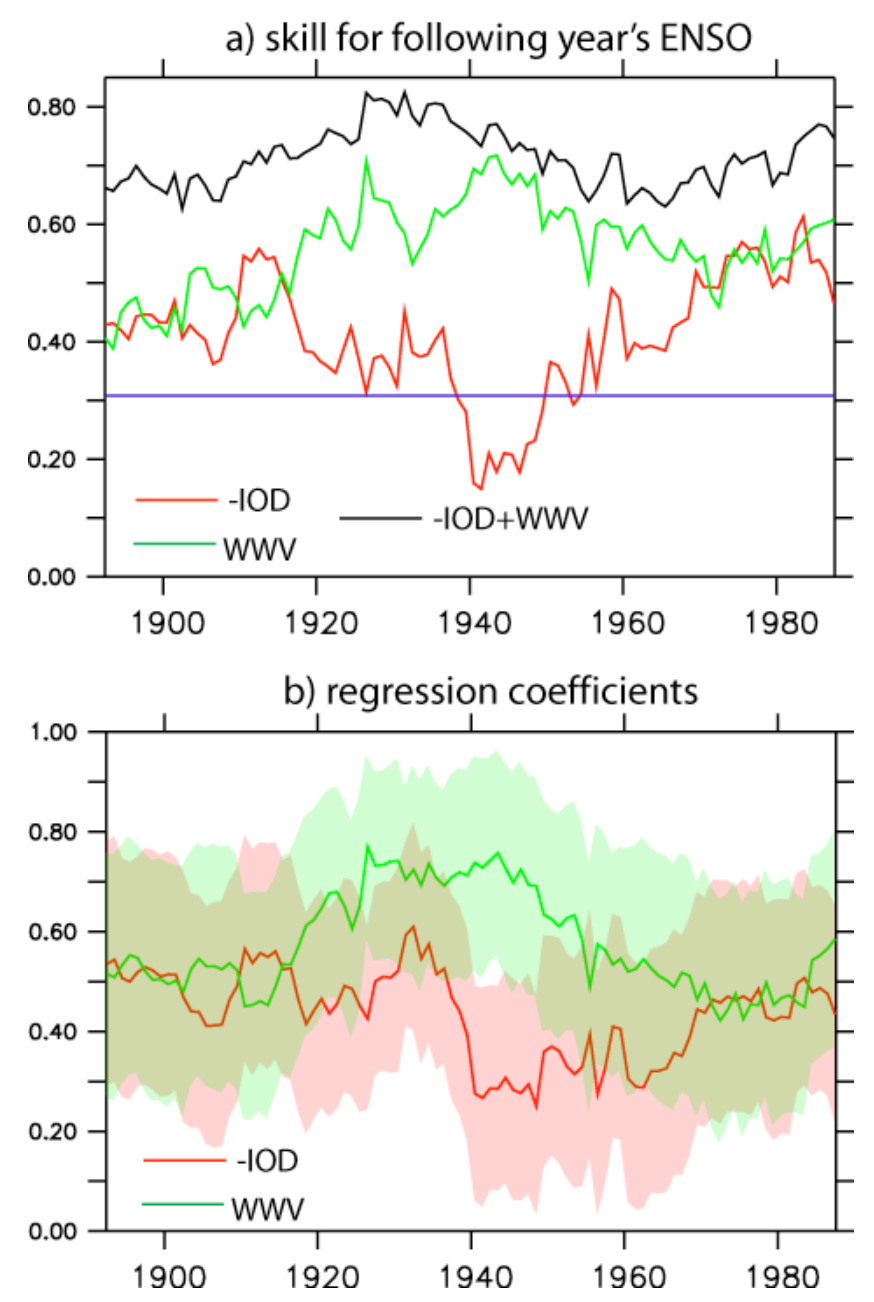

Fig. 7: Interdecadal variations for the ENSO hindcast skill using IOD and WWV. a) Skill (black) of ENSO hindcast based on previous year's $-\mathrm{IOD}_{\text {hist }}$ and $\mathrm{WWV}_{\text {hist }}$, and correlations of previous year's $-\mathrm{IOD}_{\text {hist }}$ (red) or WWV hist (green) predictors with ENSO (90\% level shown as a thin horizontal line). b) Relative contributions of the -IOD (red) and WWV (green) predictors to the model, as inferred from their regression normalised coefficients (with shading for $90 \%$ confidence intervals). 

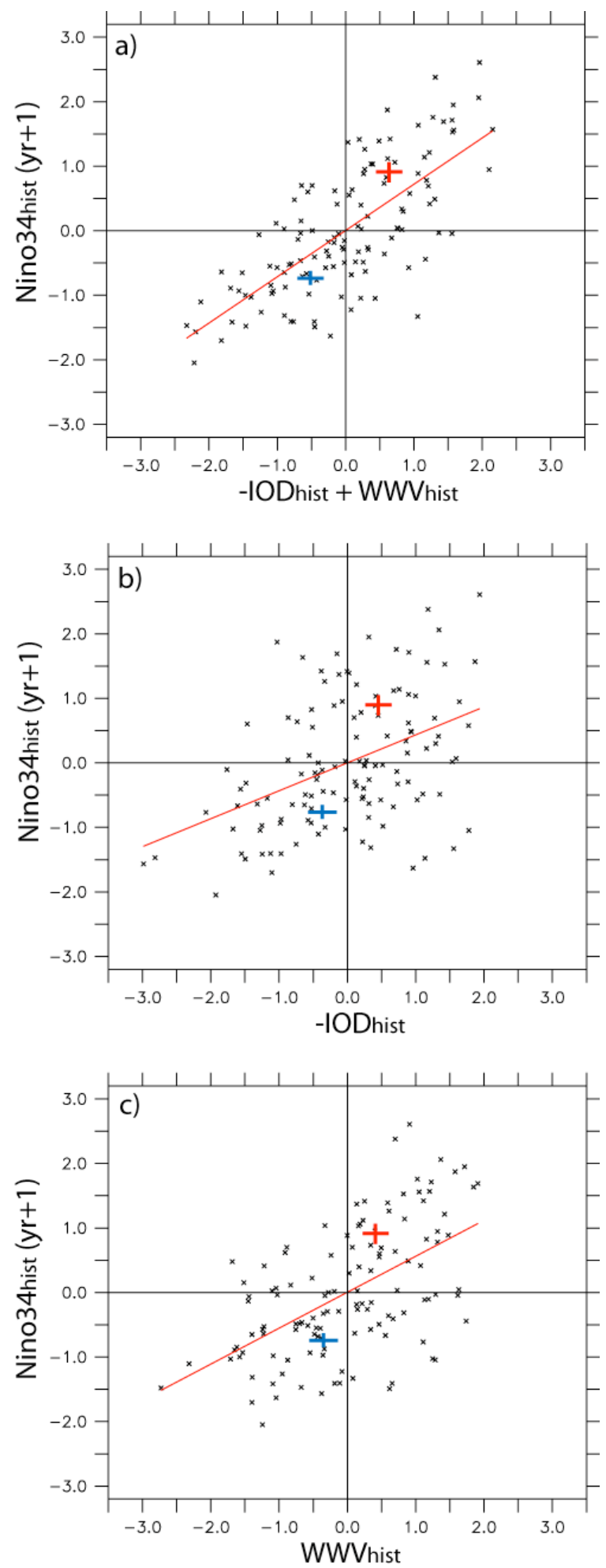

Fig. 8: Scatterplots of the Nino34hist index in NDJ one year later against a) the linear hindcast model based on WWV and $\mathrm{IOD}_{\text {hist }}$, b) $-\mathrm{IOD}_{\text {hist }}$ and c) $\mathrm{WWV}_{\text {hist }}$, over the 1872-2008 period. The red crosses show the mean (and 90\% intervals) of the points in the scatterplot upper half (i.e. El Niños) and the blue crosses: same for the lower half, when following year's ENSO phase is negative, i.e. La Niñas. All indices are normalised. These scatterplots show that IOD and WWV contributions are robust and that there is no strong asymmetry in the predictability for El Niños and La Niñas. 
a) simultaneous correlation with ENSO



b) one year-lead correlations

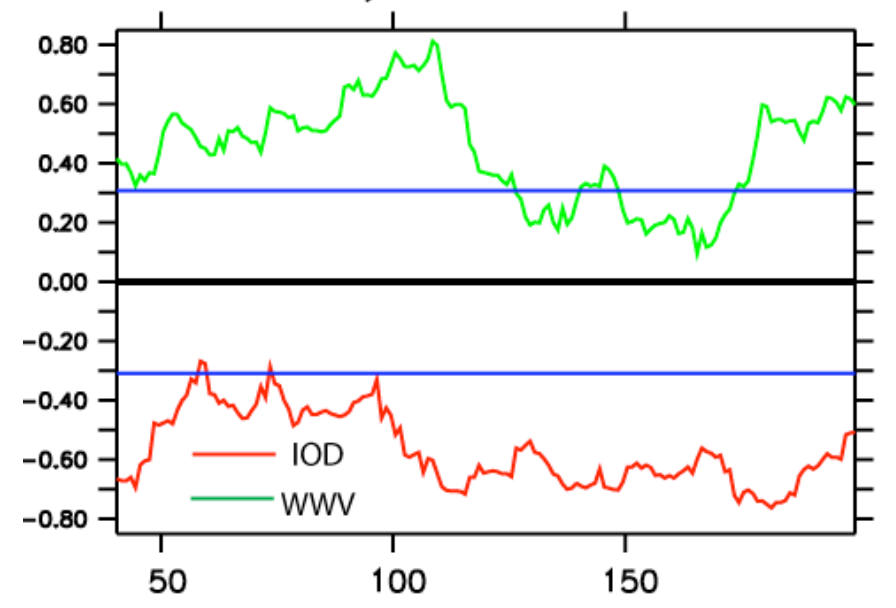

c) standard deviations

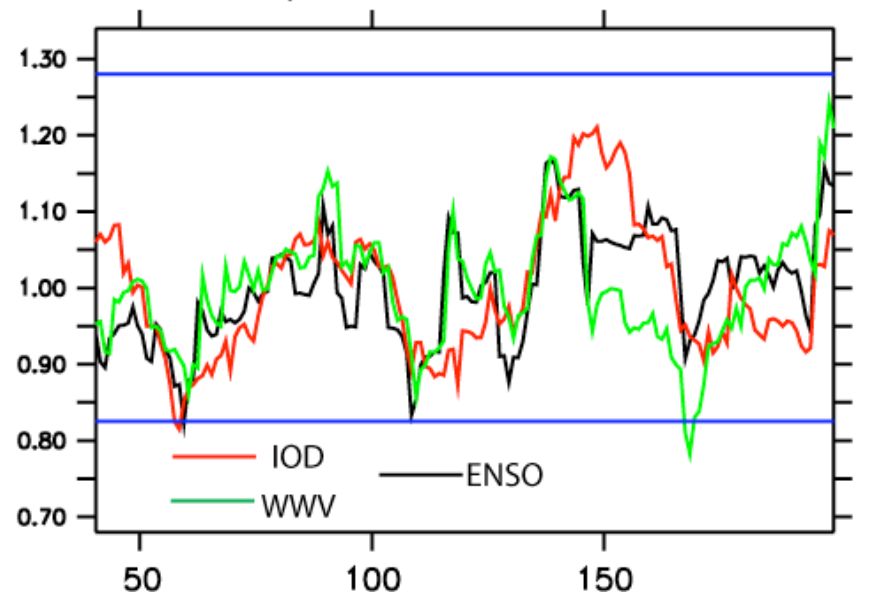

Fig. 9: interdecadal variations of IOD/WWV - ENSO relationships in the CGCM. As in Fig. 5 (e.g. red for DMI, green for WWV) but here for the SINTEX-F model. 
a) skill for following year's ENSO

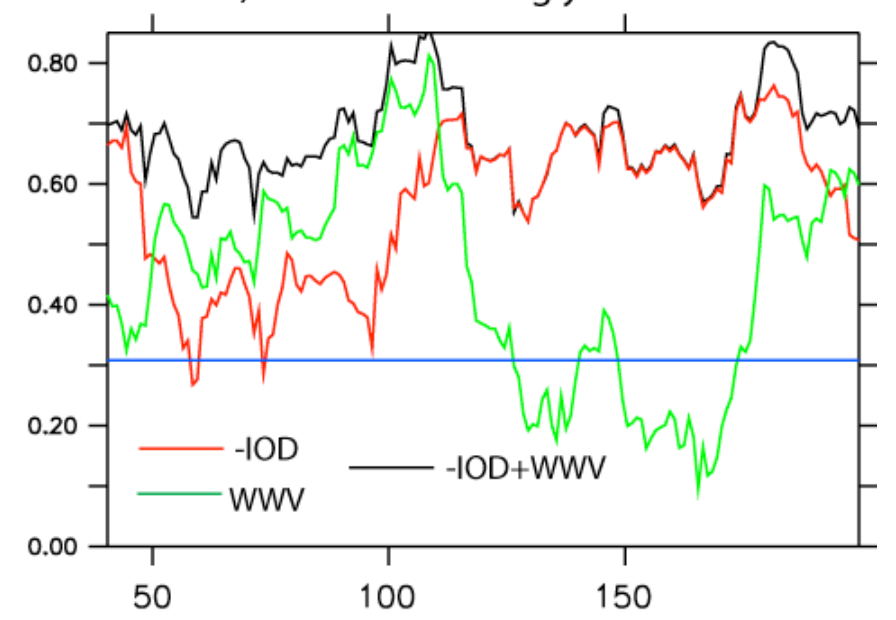

b) regression coefficients

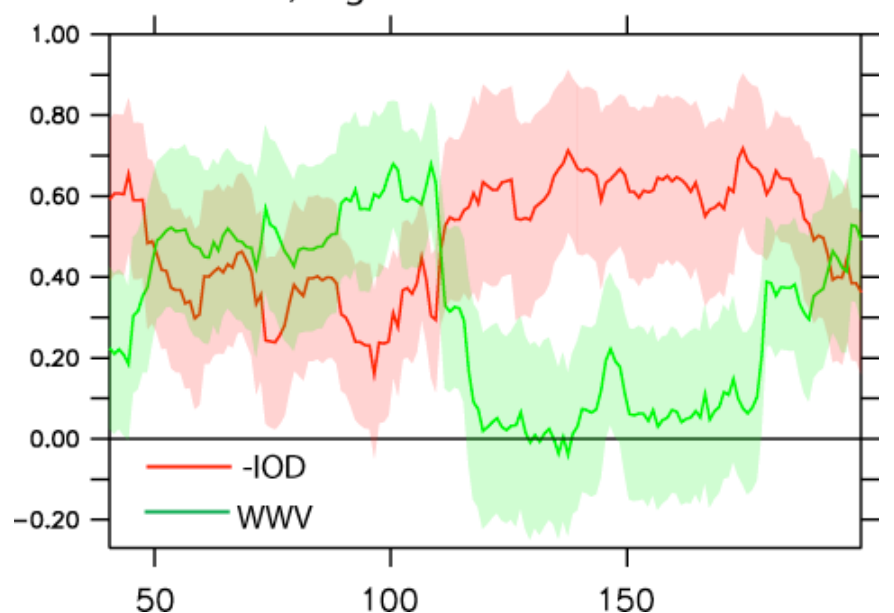

Fig. 10: Interdecadal variations for ENSO hindcast model using IOD and WWV in the CGCM. As in Fig. 6 but for the SINTEX-F model. 


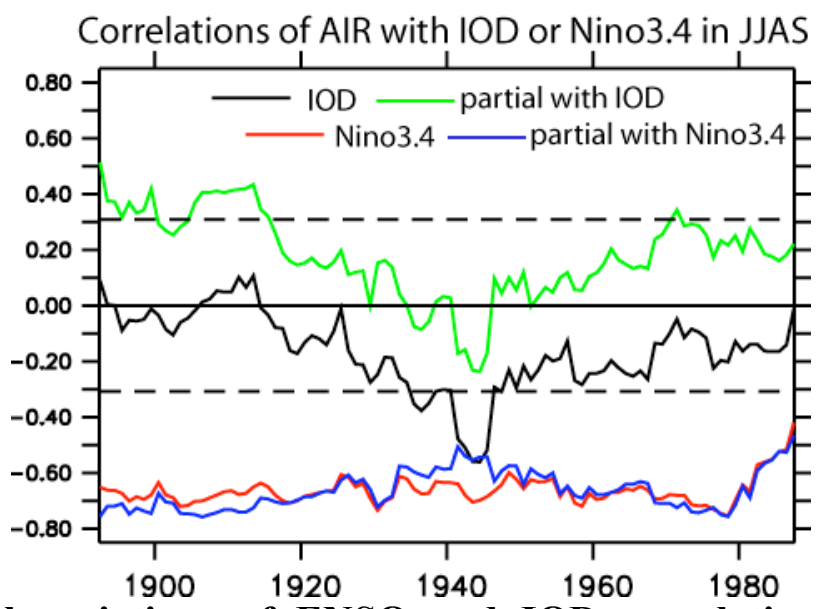

Figure 11: Interdecadal variations of ENSO and IOD correlations with Indian summer

monsoon. Simple/partial simultaneous correlations of Indian monsoon (AIR in JJAS) with IOD $\left(\mathrm{IOD}_{\text {hist }}\right.$ in JJAS; simple correlation in black and partial correlation in green) or ENSO (Nino3.4 hist $_{\text {; }}$ simple correlation in red and partial correlation in blue) for 30 years sliding windows. Horizontal lines show the $90 \%$ significance level. 




Fig. 12: Schematic of the various discussed interactions between ENSO, IOD and the Indian summer monsoon. The outer yellow-green arrows symbolise intrinsic ocean-atmosphere dynamics in the tropical Pacific: the slow ENSO discharge-recharge oceanic process. The pink arrows indicate the simultaneous effect of ENSO on same year's IOD and the delayed effect of the IOD on the following year's Pacific through the Walker circulation and the mechanism proposed in I10. Dark red and blue arrows indicate respectively positive and negative influences, i.e. of IOD positive feedback on simultaneous ENSO, of ENSO on Indian monsoon rainfall, and between ENSO and IOBW. The thin light arrows indicate the issue concerning interactions between monsoon and IOD. 
Correlation of land precipitation and sea level pressure in NDJFM:

a) with simultaneous ENSO

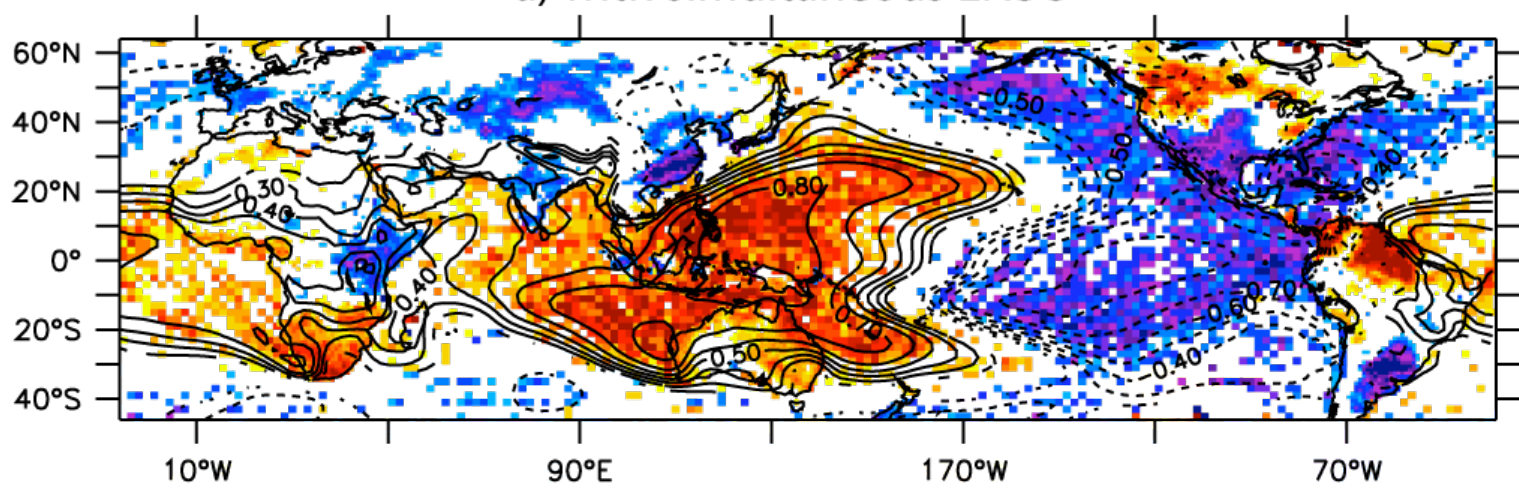

b) with the ENSO hindcast based on previous year's -IOD and WWV



Fig. 13: Example of application (+ observationally-independent historical validation) of IOD and WWV influences on following year's ENSO, to hindcast at one-year lead global land rainfall and SLP in boreal winter. a) Correlation of land precipitation (color on land, with sign reversed, i.e. dry in red, wet in blue; GPCC, 1901-2008) and SLP (color on oceans, from I-COADS; black contours from 20CR reanalysis) in NDJFM with simultaneous Nino3.4 hist. b) the same but with Nino3.4 hindcast estimate based on previous year's $-\mathrm{IOD}_{\text {hist }}$ and $\mathrm{WWV}_{\text {hist }}(\mathrm{SON})$. Only signals significant at the $90 \%$ level are shown. ENSO has significant impacts on rainfall and SLP globally (panel a). Hence, IOD and WWV, by influencing following year's ENSO, have indirectly significant delayed global impacts on rainfall, and so have a significant skill to predict globally rainfall with a one-year lead (panel b). We found such significant skill globally also for other seasons until the following spring, i.e. with a 1.5 year lead, for SST or 20CR precipitation over 1872-2008. As examples, the correlation skill to hindcast following year's precipitation is $0.46 / 0.45$ over central-northwest America $\left(15^{\circ} \mathrm{N}-35^{\circ} \mathrm{N}\right.$, west of $\left.95^{\circ} \mathrm{W}\right), 0.30 / 0.41$ over southern Africa (south of $20^{\circ} \mathrm{S}$ ) using GPCC/20CR dataset in NDJFM, and 0.39 for All Indian Rainfall in JJAS, all significant at the $99 \%$ level. 